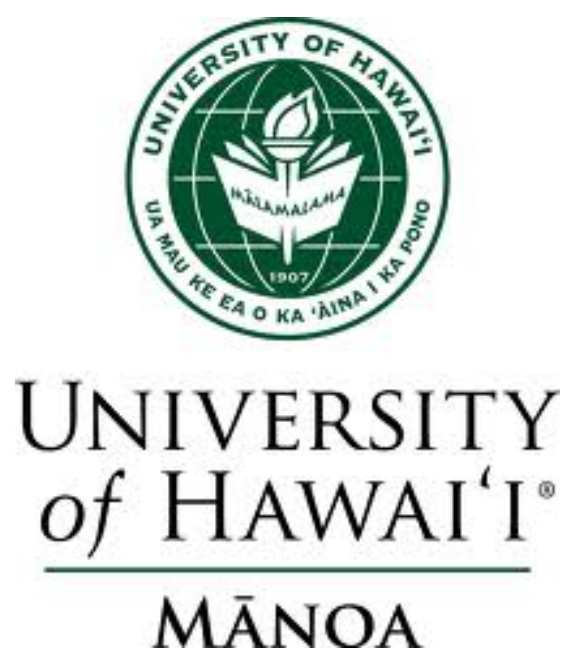

University of Hawai 'i at Mānoa Department of Economics Working Paper Series

Saunders Hall 542, 2424 Maile Way, Honolulu, HI 96822

Phone: (808) $956-8496$ www.economics.hawaii.edu

Working Paper No. 12-6

The Effect of Minimum Legal Drinking Age Restrictions on Teenage Pregnancy and Pregnancy

Outcomes

By

Inna Cintina

April 2012 


\title{
The Effect of Minimum Legal Drinking Age Restrictions on Teenage Pregnancy and Pregnancy Outcomes
}

\author{
Inna Cintina, $\mathrm{PhD}$ \\ University of Hawaii Economic Research Organization \\ 2424 Maile Way, 540 Saunders Hall \\ Honolulu, HI 96822
}

February 21, 2012

\begin{abstract}
I estimate the effect of state minimum legal drinking ages (MLDA) on teen pregnancy, birth, and abortion rates using individual level data from the National Longitudinal Survey of Youth. Results from a discrete-time hazard model indicate that a decrease in the MLDA below 21 years increases the probability of pregnancy among black teens and, surprisingly, decreases the probability of pregnancy among Hispanics. Yet, the effect on white women is statistically insignificant. I find evidence of a link between pregnancy outcome and changes in the individual alcohol consumption eligibility status at the time of pregnancy. A similar, yet statistically weaker, association is observed for changes in the MLDA at the time of pregnancy.
\end{abstract}

Keywords: Minimum legal drinking age; Alcohol; Teen pregnancy; Teen births; Teen abortions; Discrete-time hazard model

JEL classification code: J13; J18

Tel: +1 808956 8791; E-mail address: icintina@hawaii.edu

I thank Paul W. Wilson, Thomas Mroz, Sumner La Croix, Sang-Hyop Lee, and Petru S. Stoianovici for their advice and comments. 


\section{Introduction}

Numerous studies associate teenage alcohol consumption with increased motor vehicle accident mortality, sexually transmitted diseases, date rape, and other risky behaviors with long-term consequences. I analyze the effect of alcohol consumption restrictions measured in terms of the state minimum legal drinking age (MLDA) on teen pregnancy rates and pregnancy outcomes. Understanding the causes of teen childbearing is crucial for designing effective public policy. Among other adverse consequences, teen childbearing lowers human capital accumulation for teen mothers and affects their lifetime earnings (Fletcher and Wolfe 2008).

The causal effect of teen alcohol use on teen pregnancy is thought to be mediated through risky sexual behavior (Dee 2001 and Sen 2003). Several studies report that sexually active teens under the influence of alcohol are less likely to use contraception (Markowitz et al. 2005) and are hence more likely to experience an unintended pregnancy. If easy availability of alcohol leads to a higher likelihood of unintended pregnancy then this increase in the number of pregnancies could result in a relatively larger increase in the number of abortions than live births, as unintended pregnancies are more likely to be terminated than planned pregnancies (Finer and Henshaw 2006). Strict restrictions on alcohol availability, on the other hand, should be associated with a decrease in the number of pregnancies, births, and/or abortions. Although plausible, this hypothesis has received weak empirical support. Dee (2001) reports that an increase in the MLDA to 21 years - which represents a decrease in availability of alcohol decreases state level birth rates among black 15-19 year-old teens, but does not have an effect on white teens.

Some studies suggest that risky sexual behavior depends on the intensity of alcohol intake per unit of time and the context in which the alcohol is consumed (O'Hare 2005). For example, moderate alcohol consumption in a bar has different implications than binge drinking at a party. Legal restrictions that limit adolescent freedom to consume alcohol might create a rebellious response expressed in increased efforts to 
acquire alcohol and binge drinking instead of moderate drinking. ${ }^{1}$ If more restrictions on alcohol consumption increase the likelihood of more intense drinking in the private setting where intimacy is likely to occur, then there could be a relatively large number of unintended pregnancies and abortions in the presence of a high MLDA and a decrease when restrictions are relaxed. These are the opposite effects that many policy-makers might expect.

I test the relationship between the drinking eligibility restrictions and the fertility of young women using exogenous variations in the MLDA across states in the 1970s and 1980s. ${ }^{2}$ There are several novel contributions of my paper to the existing alcohol/teenage fertility literature. Unlike a few related studies that examine the relationship between alcohol consumption restrictions and fertility of 15-19 year-old teens using state level aggregate data, I use micro-level data from the 1979 cohort of the National Longitudinal Survey of Youth (NLSY). The NLSY micro-level panel allows for the reconciliation of state-level alcohol policy variables with individual fertility variables such as occurrence of pregnancy, allowing me to control for individual characteristics which are not captured or are not adequately controlled for by aggregate data. Such precision is not possible with annually aggregated fertility data. In addition, in contrast to the literature focused only on pregnancy outcomes (i.e., births or abortions), I explicitly model the effect on teen pregnancies. Finally, I analyze the effect on different race-age groups. This is not feasible with aggregate data as historical abortion data, which are needed for calculation of pregnancies, are not systematically reported by state, year, race, and age.

Using the same approach as in the existing literature, I limit my analysis to the MLDA restrictions for beer as it is the most popular alcoholic beverage among youth (Coate and Grossman 1988). Prior to 1988, the MLDA restrictions were regulated at the state-level creating considerable variation across states, with the lowest age requirement set at 18 years and the highest at 21 years of age. Between 1970 and 1975, the number of states with a MLDA below 21 years increased from 18 to 39 states. However, under the

\footnotetext{
${ }^{1}$ See Allen et al. (1994) for a review of the literature on this topic.

${ }^{2}$ Decreases in the MLDA across country in the early 1970s were alongside a decrease in the voting age; increases in the 1980s were likely compelled by the federal law requirements.
} 
threat of losing Federal highway funding, by July 1988 the MLDA was raised and set uniformly across the United States to 21. The pattern and degree of increase in the MLDA vary across time and states, allowing me to separate the effects of alcohol consumption eligibility restrictions on incidences of teen fertility. The changes in the MLDA for beer by state from 1970 to 1990 are summarized in Appendix A. Additionally, in 1973, after the Supreme Court ruling in Roe v. Wade, abortions became legal on the national level, significantly reducing the cost of unintended pregnancy for women nationwide. $^{3}$

The empirical analysis relies on a discrete-time hazard model using the microlevel monthly fertility data. Two measures of eligibility restrictions are used: an indicator of whether a woman resides in a state with the MLDA below 21 years and an indicator of whether a woman can legally drink, given her age and the MLDA in the state of residence. The former variable is consistent with the literature; the latter variable provides a more precise measure of person-specific eligibility that might not be captured by the MLDA dummy. Using predicted probabilities, I evaluate the effect of the change (decrease or increase) in the MLDA and the effect of becoming legally eligible to drink on the probability of becoming pregnant for the first time separately for 15-20, 15-17, 1820, and 21-23 year-old white, black, and Hispanic women. The effect on 15-17 year olds who are not legally eligible to drink under any MLDA regime might differ from the effect on 18-20 year olds who are directly affected by the MLDA variations. If so, then the aggregation into a larger age group might wipe out this variation. Given the information about pregnancy outcome and the MLDA restrictions at the time of pregnancy, I evaluate the effect of changes in the eligibility restrictions on the outcome (i.e., live birth or abortion) of first pregnancy. Identifying possible effects of the changes in the MLDA is of high priority in light of ongoing debate regarding the effects of the MLDA. $^{4}$

\footnotetext{
${ }^{3}$ Abortion laws are discussed in Gold (2003). The pill, introduced in the 1960s, might have affected teen childbearing rates. Despite being the most effective method of contraception used by the sexually active teens in the 1970s, it also had a high misuse rate (see Jones and Darroch Forrest 1989).

${ }^{4}$ In recent years more than 100 higher education leaders supported the Amethyst Initiative - a public statement that calls for informed and unimpeded debate on the 21 year-old MLDA.
} 
The results indicate that a decrease in the MLDA to 18, 19, or 20 years significantly increases the probability of becoming pregnant for the first time by 3.9 percentage points among 15-20 year-old black women. This is a substantial effect given that the base probability for this age group is 8.7 percent. An almost identical effect is observed for 15-17 year old blacks. The probability of pregnancy among 15-20 year old Hispanics, on the other hand, decreases by 8.8 percentage points when MLDA decreases. This effect is even stronger for 18-20 year olds. Finally, changes in the MLDA do not affect pregnancy rates among white women.

I do not find strong evidence in support of the hypothesis that the MLDA per se at the time of first pregnancy affect the outcome of that pregnancy. Yet, changes in the legal eligibility status among 18-20 year women appear to significantly alter pregnancy outcome decisions among white and Hispanic women, but not their black peers. Specifically, becoming legally eligible to drink alcohol decreases the probability of abortion and increases the probability of live birth among whites. The reverse is observed for Hispanics. There is at least one explanation that reconciles these findings. Becoming legally eligible to drink expands the set of activities that 18-20 year-old teens can do freely without the fear of being caught. Eligible teens might prefer alcohol consumption at the bar to binge drinking at someone's house. ${ }^{5}$ If this is the case, then it is likely that changes in the alcohol consumption behavior are caused by changes in the individual eligibility status rather than by changes in the state MLDA that might not be binding for a given individual.

Overall, the mixed nature of the results does not permit to favor either one of two hypothesized mechanisms. Since the direction of the effect in the pregnancy model varies across races, it is possible that the mechanism that links alcohol consumption patterns and risky sexual behavior differs across races as well. I find that birth and abortion rates are significantly affected by alcohol consumption eligibility status at the time of pregnancy rather than the MLDA in the state of residence at the time of pregnancy. This could mean that the MLDA alone might not be an adequate measure to

\footnotetext{
${ }^{5}$ Wechsler et al. (2000) reports some evidence in favor of this hypothesis. The underage students tend to drink less often but more drinks per occasion; they are also more likely to drink in private settings.
} 
capture alcohol consumption behavior and one should account for the intensity, location, and legality of alcohol consumption as well.

\section{Literature review: Alcohol consumption and teenage fertility}

Teen demand for alcoholic beverages is relatively responsive to changes in alcohol consumption availability restrictions. Most studies conclude that a decrease in restrictions on alcohol consumption as well as a decrease in taxation that affects prices of alcoholic beverage leads to an increase in teen alcohol consumption. ${ }^{6}$

Despite the positive association between alcohol use and risky sexual behavior among teenagers reported in numerous studies, the causal nature of the relationship remains unknown. ${ }^{7}$ Results drawn primarily from aggregate data can only assume that occasions of alcohol use and risky sex coincide; event specific studies, however, do provide some evidence in favor of an association for young heterosexuals (Donovan and McEwan 1995). Some studies report that alcohol use may lower contraception use among sexually active teens, and, hence, increase the probability of an unplanned pregnancy (e.g., Grossman and Markowitz 2005; Markowitz et al. 2005; Hingson et al. 1990, and Rees et al. 2001).

A few recent studies based on aggregate data have emphasized the relationship between alcohol consumption restrictions and teen fertility. Using a "difference-indifference-in-difference” model, Dee (2001) finds that the nationwide increase in the MLDA to 21 reduced the birth rate among black 15-19 year-old teens by roughly 5.5 percent; the effect on white teens is mostly statistically insignificant and "implausibly" signed. Dee suggests that underlying differences in patterns of sexual behavior and alcohol consumption could explain variation in racial childbearing patterns and racespecific responses to changes in drinking age. Sen (2003) investigates the effects of beer taxes and other alcohol-related policies, including the MLDA, on teen pregnancy outcomes (i.e., abortion and birth). The MLDA does not appear to have a robust,

\footnotetext{
${ }^{6}$ Grossman et al. (1994), Coate and Grossman (1988), Dee and Evans (2003); for exceptions see Dee (1999), Kaestner (2000). Literature review on the topic is presented in Wagenaar et al. (2009) and Wagenaar and Toomey (2002).

${ }^{7}$ See Leigh and Stall (1993) and Rashad and Kaestner (2004) for the literature review.
} 
statistically significant impact on either outcome. One should be cautious with the interpretation of these results as Sen's study relies on four years of data (i.e., 1985, 1988, 1992, and 1996), and only the period from 1985 to 1988 involves variation in the MLDA. ${ }^{8}$

Both Dee (2001) and Sen (2003) use state-level panel data on birth rates and abortion rates. The main disadvantage of this approach is that it does not permit a thorough analysis of the effects of external factors at the time of pregnancy on individual decision making. Results presented by Dee (2001) only partially support the hypothesis that a low MLDA leads to higher childbearing rates among teenagers and indicate that the response differs across races. I capture the relationship between alcohol consumption eligibility restrictions and teen fertility using the micro-level monthly fertility data that allows me to incorporate individual characteristics in the analysis as well as control for the state policy at the time of pregnancy. Although at the preliminary stage I considered aggregate data as well the discussion is mostly limited to highlighting disadvantages of aggregate data.

\section{Empirical analysis}

The preliminary analysis of state level pregnancy, birth, and abortion rates for the period 1974-1988, using the difference-in-difference model, do not provide strong evidence that lower MLDA has a significant positive impact on aggregate teen fertility rates. ${ }^{9}$ The results are not surprising. If there is a differential response to changes in the

\footnotetext{
${ }^{8}$ In addition, other results reported in the study are highly sensitive to the choice of covariates. For example, in models with state fixed effects, an observed negative effect of beer tax on teen abortion rate becomes statistically insignificant.

${ }^{9}$ The aggregate data on abortions (and hence pregnancies) are mostly absent prior to 1974 . The set-up and results of the difference-in-difference model are reported in Appendix B. In brief, the model specification is following: the treatment group - 15-19 year-old women; control groups - 20-24 and 25-29 year-old women, and the event - the MLDA in a state is set to 18 or 19 years. The dependent variable is the natural logarithm of the pregnancy or birth or abortion rate per 1,000 women in the corresponding age group in a state-year. Each model includes state unemployment rate, state beer tax, per capita personal income, the maximum AFDC benefit level, controls for the presence of Medicaid funding restrictions for abortion and enforced parental involvement laws for minors, controls for the border state policies regarding alcohol consumption and parental involvement laws, a number of abortion providers as well as a full set of state and year fixed effects. Results indicate that the point estimates of the effect of low MLDA on teens are
} 
MLDA restrictions across racial groups (as suggested by Dee 2001) the aggregation might wipe it out.

In addition, aggregate data on abortions and pregnancies might not be informative for three reasons. First, abortion data are not available by state, year, age group, and race. Therefore unlike Dee (2001), one neither can construct abortion rates by race nor estimate separate models for each race. Second, the state level data on abortions are collected by the Center for Disease Control and Prevention (CDC). However, due to a lack of a uniform reporting requirement across states, some states do not report abortions by age groups or do not report them at all or on a continuous basis. This alone introduces a substantial number of missing values in the data. Both above mentioned points can be applied to pregnancy rates, calculation of which involves use of abortion data. Third, abortion data available from CDC reflect abortions by the state of occurrence (i.e. a state where abortion took place) and not by the state of residence. The latter is more precise as it allows one to study the effect of changes in the law in a given state on the rates in the same state. The abortion statistics collected by the Alan Guttmacher Institute (AGI) is by state of residence. However, these data are not available by age group.

Since aggregate data on childbearing makes it difficult to study the policy effects that differ across race-age groups, a proper policy analysis should rely more on disaggregated data that permits a separation of the effects by race and by age of the individual.

Data

I use the 1979 cohort of the NLSY that consists of a nationally representative random sample of young men and women who were 14 to 22 years old in 1979 and oversamples of young blacks, Hispanics, poor whites, and members of the military. In addition to the vast amount of personal information, the NLSY provides detailed retrospective fertility and mobility histories which allow one to track the timing of the

weak in both a statistical and a substantive economic sense. The exception is teen abortion rate. However, this result is sensitive to the choice of control group and covariates. 
first pregnancy and its outcome (birth, abortion, miscarriage/stillbirth) for 6,283 women and to identify the location (state) of each woman at the time of that pregnancy.

The identification of pregnancy incidence relies on information regarding the reported number of pregnancies and their outcomes. Abortions are underreported in the NLSY data, especially in the earlier survey years (Jones and Darroch Forrest (1992)). For example, Udry et al. (1996) report that blacks and Hispanics are significantly less approving of abortion in a variety of circumstances than whites, and these differences translate into different propensities to report. In order to address this issue I estimate models separately for whites, blacks, and Hispanics.

The timing of events becomes of high priority when one attempts to study the effect of the change in the state policy on individual decisions. The move to the new location, the pregnancy, and the change in the alcohol consumption restrictions can happen at any time during the year. To make my analysis as precise as possible, I combine retrospective information and data obtained from the 1979-1988 annual surveys and convert the NLSY data set into a panel where the unit of observation is a personmonth.

Each woman enters my data set in the month when she turns 15 years old. For every month after entry, I know whether she became pregnant or not, her state of residence, and the MLDA in that state. Once she turns 21 years old she exits the data set, as past this age drinking age restrictions are not binding. Further restrictions include exclusion of women with incomplete fertility history, women serving in military, women in the poor white oversample, and women who had their first pregnancy before their $15^{\text {th }}$ birthday. The final sample includes 337,680 monthly observations during the period 1972-1985 on 4,690 women. Half of my sample is white women, one-third is black, and the rest are Hispanics.

The person-month data set can be viewed as transition data in which women move from one state (being not pregnant) to another (becoming pregnant). Table 1 presents the narrative history of the pregnancy occurrence and its outcome over time for 15-20 year-old women described in terms of hazard and survival functions as well as 21- 
23 women for comparison. Among 4,690 women at risk of first pregnancy, almost 5\% became pregnant while being 15 years old, among all 16 years old at risk - 7\%, etc. Examining the sample survival probabilities, we see that 95\% of all women did not have their first pregnancy at age $15,81 \%$ - did not experience a pregnancy by their $18^{\text {th }}$ birthday, and slightly more than half of the sample did not have a first pregnancy by their $21^{\text {st }}$ birthday. I treat all women who did not have their first pregnancy before their $21^{\text {st }}$ birthday $-2,718$ women or $58 \%$ of my data set - as censored observations.

About 75\% of all first pregnancies that occurred to 15-20 year-old women ended in birth and approximately $16 \%$ were terminated. Inspection of composition of pregnancies aggregated by race, age, and outcome reveals that on average about a quarter of all first pregnancies among white women is terminated (compared to about 10\% among blacks and 13\% among Hispanics). The majority of black and Hispanic women in my dataset had a live birth (about $82 \%$ of blacks and $78 \%$ of Hispanics). For white women this number is much smaller (66\%).

\section{Model specification: Discrete-time hazard}

The fertility history data identify the month and year when pregnancy occurs. This suggests grouping observations into discrete (monthly) time intervals that cover period from January 1972 through December 1985. Given the nature of the observed data, I use the discrete-time hazard model. Vast literatures exist on discrete-time models of event history data (e.g., Allison 1982; Singer and Willett 2003; Box-Steffensmeier and Jones 2004); here, I briefly discuss the main concept of these models.

Recall that I examine whether the alcohol consumption eligibility requirements affect timing of first pregnancy among teens. The occurrence of first pregnancy at time $t$ is a non-repeatable event and intrinsically conditional on not experiencing the event at any time period prior to $t$. Let $T$ denote the discrete random variable whose values $T_{i}$ indicate the time period $t$ when the $i^{\text {th }}$ woman experiences her first pregnancy. The conditional probability that a randomly selected woman $i$ in state $s$ will experience her 
first pregnancy in period $t$, given both that the event has yet to occur and a set of covariates, is defined as

$$
h_{i s t}=\operatorname{Pr}\left[T_{i}=t \mid T_{i} \geq t, X_{i s t}\right],
$$

where $h_{i s t}$ denotes the conditional probability of first pregnancy.

For each woman the dependent variable that indicates whether she is pregnant for the first time can be represented as a string of zeros (indicating not pregnant) followed by a one (indicating pregnancy). If a woman did not have pregnancy prior to age 21 then the dependent variable is represented only by a string of zeros implying that the event has yet to be experienced. The binary nature of the outcome and the specification of the loglikelihood function allow one to model the hazard probability as a probit function. ${ }^{10}$ Letting 1 st_time_pregnant ${ }_{i t s}$ denote a binary indicator of the pregnancy status of woman $i$ in state $s$ at time $t$, the discrete hazard can be written as

$$
h_{i s t}=\operatorname{Pr}\left[1 \text { st_time_pregnant }{ }_{i s t}=1 \mid \text { not pregnant before } t, X_{i s t}\right]=\Phi\left(\beta^{\prime} X_{i s t}\right),
$$

where $\Phi$ is the standard cumulative normal distribution function and $X$ is a vector of covariates.

The presence of several age cohorts in my data set and the question at hand determines two notions of time: age-time and calendar time. For each woman in my data set I observe the age when she had her first pregnancy (which also corresponds to a certain calendar time $t$ ). I normalize age by expressing it in terms of months since birth minus 180 so it corresponds to months since age 15 . To account for the effect of calendar time $t$, I include a full set of calendar time fixed effects. Equation (2) can be easily modified to accommodate both notions of time. Let, in addition to the index for calendar time $t$, introduce age counter $\tau$ that represents the time that a woman spends at risk of first pregnancy measured in months (subject to normalization discussed above). Then $h_{i s t}$ is

$$
\operatorname{Pr}\left[1 \text { st_time_pregnant } t_{\text {ist }}=1 \mid \text { not pregnant before } t, X_{i s t}\right]=\Phi\left(\beta^{\prime} X_{i s t}+g\left(\tau_{i s t}\right)+\eta_{t}\right),
$$

where the function $g(\cdot)$ is parameterized as a cubic polynomial that captures the "left over” effect of age on the hazard probability after accounting for covariates.

\footnotetext{
${ }^{10}$ Allison (1982) shows that the log-likelihood function for the discrete-time hazard is the log-likelihood function for the regression analysis of dichotomous dependent variables. Therefore, it is a common practice to use logit or probit link functions in estimation of discrete-time hazard models.
} 
Empirically the discrete-time (monthly) hazard probability of first pregnancy (pregnancy model) is given by the following baseline specification

$$
\begin{array}{r}
\operatorname{Pr}\left[1 \text { st_time_pregnant } t_{i s t}=1 \mid \text { not pregnant before } t, X_{i s t}\right]= \\
=\Phi\left(\beta_{0}+\delta \text { ELIGIBILITY_RESTRICTION }{ }_{i s t}+\beta^{\prime} X_{i s t}+\right. \\
\left.\theta_{1} A G E_{i t}+\theta_{2} A G E_{i t}{ }^{2}+\theta_{3} A G E_{i t}{ }^{3}+\gamma_{s}+\eta_{t}\right),
\end{array}
$$

where $i$ indexes individuals, $s$ indexes state of residence, $t$ indexes calendar time that corresponds to a combination of month and year and ranges from January 1972 to December 1985.

I use two measures of eligibility restrictions to capture the effect of the MLDA on teen fertility: a dummy indicating whether the MLDA in a state of residence is set below age 21 and an indicator of whether a teen can legally drink in the state of residence. ${ }^{11}$ The former addresses the question of whether being in the state with the MLDA below age 21 affects the probability of first pregnancy among teens, and the latter asks whether being legally eligible to consume alcohol affects the probability of first pregnancy and can be helpful in identifying channels through which the legal age restrictions affect teen behavior. Some states increased the MLDA while allowing a "grandfather clause," a provision that exempts teens who were previously eligible to drink from new eligibility requirements. If a female is "grandfathered" by the law, my "legally eligible” dummy reflects this minutia. According to Table 2, which provides a descriptive statistics for the variables of interest, about $71 \%$ of women in my sample were residing in states with the MLDA below 21 years. About one third of 15-20 year-old women in the dataset can drink legally.

The vector $X$ included in (4) contains controls for individual and family characteristics (i.e., race, religion in which female was raised, the Armed Forces Qualifications Test (AFQT) scores, whether both parent were present in the household at age 14, and mother's education). Descriptive statistics for these variables are presented in Table 2. To control for the state-specific characteristics and time effects, I include a full

\footnotetext{
${ }^{11}$ An alternative measure "MLDA is 18 or 19 years" yields estimates that are similar in terms of the sign to the ones discussed later in the text. In statistical sense, results for whites become stronger, results for Hispanics weaker and results for blacks are qualitatively similar (results are available on request).
} 
set of state dummies and year dummies as well as dummies for the calendar month to account for a seasonality effect. Other controls that were considered are the presence of an older sibling, father's education, whether a state enforces parental involvement laws, marital status of the individual, and interaction terms between eligibility restrictions and personal characteristics. Although NLSY collects data regarding the use of contraception before the first pregnancy, this variable contains a large number of non-response values (one third of women included in my data set). Since the inclusion of above mentioned variables mostly did not alter other results or improve the model's fit, I do not include them in the model. ${ }^{12}$

To test whether the effect of eligibility restrictions on the probability of first pregnancy varies across age groups and races, I estimate separate equations for white, black, and Hispanic 15-20 year-old women. The segmentation of the data set permits all estimated coefficients to vary across race groups. ${ }^{13}$ This is an acceptable substitute to a single equation model with numerous interaction terms. The preference is given to separate equations since, unlike in a linear model, the interpretation of the interaction terms in a nonlinear model is not straightforward, as the sign and the magnitude of the effect vary with the values of covariates (Ai and Norton 2003). Finally, alcohol consumption patterns might differ across age cohorts within a race. To take this into account, within each race, I estimate models separately for 15-17 and 18-20 year olds. In order to test a credibility of my model, I repeat estimation for 21-23 year-old black, white, and Hispanic women. If the model is correct then eligibility restrictions should not affect dependent variable.

Overall, as mentioned before, the eligibility restrictions could have a positive or a negative impact on the probability of first pregnancy. The former will be observed if there is a complimentary relationship between alcohol consumption and risky sex that

\footnotetext{
${ }^{12}$ Results are available on request.

${ }^{13}$ The equality of coefficients across groups cannot be easily tested in a non-linear model. The tests proposed by Allison (1999) and Long (2009) are quite restrictive. The former test relies on an assumption that the estimated coefficient for at least one variable does not vary across groups. The latter involves testing equality of the predicted probabilities across groups which might not be informative in models with a large number of covariates.
} 
increases instances of unplanned pregnancies; the latter will be observed if easy availability of alcohol affects place and intensity of alcohol consumption toward binge drinking in the private setting where risky sex is likely to occur. Also, as suggested by Fertig and Watson (2009), the MLDA restrictions might affect the composition of the pool of women who become pregnant. Since I know the outcome of the first pregnancy and the alcohol consumption eligibility restrictions in a state at the time of pregnancy, I can explore the compositional aspect by estimating the probability of abortion (abortion model) and the probability of live birth (birth model). Both models are estimated as the conditional on pregnancy probability models using a specification similar to (4). Calendar month dummies are omitted due to a relatively small sample sizes for some race-age groups; year and state fixed effects are included. State fixed effects will account for time invariant state specific factors like availability of reproductive services (for example, the more conservative states have fewer abortion providers and their number exhibits little variation over time). Similar to the pregnancy model, the vast majority of additional covariates did not substantially change other results or improve fit for either model (results available on request).

Empirical results are discussed in the next section. Since probit estimates per se do not provide meaningful information regarding the magnitude of estimated effects (Greene 1998), the general discussion is omitted. The effects of changes in eligibility restrictions are evaluated using a discrete change approach (Long 1997). The results are reported in the following order: first, I evaluate the change in the probability of first pregnancy due to a change in the MLDA for white, black, and Hispanic 15-20, 15-17, 1820, and 21-23 year-old women. Then I repeat analysis for pregnancy outcomes. Finally, I discuss the effect of becoming legally eligible to drink for white, black, and Hispanic 1820 year-old women. The effects of personal characteristics on studied probabilities have generally expected signs, but as they are of secondary interest the discussion is omitted. 


\section{Results}

I use estimated coefficients, reported in Appendix C, to calculate the predicted probabilities of first pregnancy and conditional probabilities of birth and abortion for each race-age group. According to Table 3, blacks and Hispanics of all ages have higher predicted probabilities of first pregnancy compared to their white peers. Higher probabilities of first pregnancy among black teens compared to white teens are consistent with the earlier findings that blacks start sexual activity earlier than whites (Zelnik and Shah 1983) and Hispanics tend to have higher fertility rates compared to other races (Wendel and Wendel 2004). Among pregnant women, blacks have the highest probability of birth, whites - the lowest. The highest probabilities of abortion are observed for white women, the lowest - for Hispanics.

To assess the magnitude of the effects of eligibility restrictions, I use annual predicted probabilities for each observation in each race-age group to calculate a discrete change in the probability $\left(\Delta_{i}\right)$ due to a change in eligibility restrictions. ${ }^{14}$ For example, the effect of a decrease in the MLDA for a woman $i$ in a given race-age group, and year equals the difference between the predicted probability of first pregnancy while in a state with the MLDA below 21 years and the predicted probability of first pregnancy while in a state with the MLDA set to 21 years:

$\Delta_{i}=$ predicted annual $\operatorname{Pr}\left[1\right.$ st_time_pregnant ${ }_{i s t}=1 \mid X_{i s t} \& M L D A=18$ or 19 or 20] predicted annual Pr[1st_time_pregnant $\left.{ }_{i s t}=1 \mid X_{i s t,} \& M L D A=21\right]$

Then I average the effect across observations in a given race-age group: $\bar{\Delta}=\frac{\sum_{i=1}^{N_{R}} \Delta_{i}}{N_{R}}$, where $N_{R}$ is the number of women in a race-age group $R$. Note that the change $\Delta_{i}$ is calculated for each woman given her characteristics; the MLDA, on the other hand, is exogenously assigned a certain value. The latter implies that I predict probabilities for two policy scenarios: initially the legal age is set to below age 21 for everyone in the sample then it

\footnotetext{
14 The annual probabilities might be more informative, therefore I convert individual monthly probabilities (obtained using person-month data) into annual probabilities:

$\operatorname{Pr}\left(1^{\text {st }}\right.$ time pregnant in year $\left.y\right)=1-\left[\prod_{m=1}^{12}\left(1-\operatorname{Pr}\left(1^{\text {st }}\right.\right.\right.$ time pregnant in month $\left.\left.\left.m\right)\right)\right]$
} 
is set to 21 years for everyone in the sample. To identify the effect of an increase in the MLDA one should just flip the sign of $\Delta_{i}$. In a similar manner, I calculate the average change in the predicted probability of first pregnancy due to becoming legally eligible to drink. The change in the predicted probability of first pregnancy due to a decrease in the MLDA by race-age group is reported in Table 4; changes in the predicted probability of birth and abortion for pregnant women are reported in Table 5. For space concerns results for 21-23 are omitted from the Table 5 but are available on request from the author. The standard errors for all averages are obtained using a bootstrap method.

The annual average predicted probability of first pregnancy for 15-20 year old in the presence of the MLDA set to 21 years varies from 6.4 percent for whites to 8.4 and 15.3 percent for blacks and Hispanics respectively (Table 4). A decrease in MLDA to 18 or 19 or 20 years significantly increases the probability of first pregnancy for blacks on average by 3.9 percentage points. On the other hand, the reduction of the MLDA reduces the average predicted probability of first pregnancy for whites and Hispanics, but the estimate for whites lack statistical significance. When the 15-20 year old sample is split into 15-17 and 18-20 year old samples, it appears that changes in the MLDA affect only 15-17 year-old blacks and 18-20 year old Hispanic women. Specifically, a decrease in the MLDA is associated with 4 percentage points increase in the probability of pregnancy among 15-17 year old blacks and 29.0 percentage points decrease in the probability of pregnancy among 18-20 year old Hispanics. As expected, changes in the MLDA do not affect childbearing of 21-23 year-old women.

According to results reported in the upper panel of Table 5, a low MLDA at the time of pregnancy significantly increases the (conditional) probability of birth only for 15-20 year-old white women (a change of 12.7 percentage points) and does not affect their peers of other races. With the exception of 18-20 year-old Hispanics, it appears that the same event at the time of pregnancy does not affect the probability of birth among pregnant 15-17, 18-20, and 21-23 year-old women of any race. As for 18-20 year-old Hispanics, although the estimated effect is statistically significant and indicates that the probability of abortion decreases due to a decrease in the MLDA at the time of pregnancy 
one should be cautious. A large magnitude of the effect reflects a very large (and possibly imprecise) underlying probit estimate.

I do not find evidence that a decrease in the MLDA at the time of pregnancy has a statistically significant effect on the probability of abortion (lower panel of Table 5). Results indicate that a decrease in the MLDA is associated with a decrease in the probability of abortion among pregnant white 15-20 year-old women and an increase in the probability of abortion among their black and Hispanic peers. However, these estimates have relatively large standard errors. The results for 15-17 and 18-20 year-old women are qualitatively similar and equally noisy due to small sample sizes and a large number of covariates included in the corresponding model.

The results described above are not surprising. Being in a state with the MLDA below age 21 is a relatively noisy measure of implied alcohol consumption that does not account for the fact that some teens are "grandfathered" in the dated restrictions. Also not all 18-19 year-old teens in a state with the MLDA below 21 years can legally drink. Carpenter and Dobkin (2009), using 1997-2005 data, find a large and immediate increase in drinking among young adults after becoming legally eligible to drink. Therefore, the results from a specification that includes my second measure of eligibility restrictions, an indicator for whether a woman can legally drink, that are reported in Table 6 might be more informative.

Being legally eligible to drink at the time of pregnancy significantly increases the probability of birth and decreases the probability of abortion among 18-20 year-old white women (a change of 29.1 and 14.7 percentage points respectively), but does not have a statistically strong effect on the probability of becoming pregnant for the first time. Qualitatively similar results are observed for Hispanic women, but the direction of the effect is reversed. Specifically, pregnant 18-20 year-old Hispanics who are legally eligible to drink have a lower probability of live birth and a higher probability of abortion than their ineligible Hispanic peers and these differences are statistically significant. As for 18-20 year-old black pregnant women results indicate that change in the eligibility status at the time of first pregnancy does not affect the probability of either outcome. 
Results from this model are consistent in terms of the sign with the ones reported for 1820 year olds in Table 4 and Table 5.

Results presented here are different from those reported in Dee (2001). For example, I find that a decrease in the MLDA increases the probability of first pregnancy among black teen women (specifically among 15-17 year-olds) but I do not find evidence that it also increases the birth rates among blacks. I also find that the MLDA below age 21 at the time of pregnancy increases the probability of live birth among white 15-20 year old women. The difference in results is not astounding given the differences in data and explanatory variables used: Dee analyzes the effect on 15-19 year-old women by race controlling for state-level characteristics and the MLDA restrictions prevailing during a given year; I analyze the effect on 15-20, 15-17, and 18-20 year-old women by race controlling for individual characteristics and the MLDA restrictions at the time of pregnancy. Further, my results are robust for samples that are restricted to 15-19 year old women of a given race (results are not reported here, but available on request).

\section{Conclusion}

Changes in the MLDA across states in the 1970s and 1980s, in conjunction with the legalization of abortion, can alter the alcohol-induced risky sexual behavior. We would expect to observe higher pregnancy, birth and/or abortion rates in states with a relatively low MLDA and the opposite when the MLDA is high. The evidence presented in the literature, primarily drawn from the aggregate state level data, indicates that an increase in the MLDA to 21 years affect only black teen birth rates, but not the birth rate of their white peers. Underlying cultural differences and differences in patterns of sexual behavior and alcohol consumption might be part of the explanation. Yet, changes in the MLDA may affect the choice of the location where alcohol consumption takes place and the intensity of alcohol intake. For example, the relatively high MLDA could induce binge-drinking among the underage which usually takes place at the private gatherings where risky sexual behavior (including unprotected sex) is more likely to occur. If so, we might observe higher pregnancy, birth, and/or abortion rates after an increase in the 
MLDA. Results reported in Naimi et al. (2003) suggest that implications of binge drinking also can vary across races.

I use a discrete-time hazard model that relies on individual level data from the NLSY to test whether easing alcohol availability, measured in terms of whether there is a decrease in the MLDA (to 18,19 or 20 years) and whether becoming legally eligible to drink, leads to a change in teen pregnancy rate or pregnancy outcome. This paper improves the existing literature on alcohol/teen childbearing, as the previous related studies draw conclusions from aggregated data alone and study birth and abortion rates rather than pregnancy rates. The micro-level data have advantages over state level aggregate data as it allows me to reconcile state level alcohol policy variables at the time of pregnancy with individual fertility decisions and to control for the individual characteristics. The effects of alcohol policy might differ across race-age groups. Yet, with the exception of birth rates, state level aggregate fertility rates are not available by race. Given the limitations of aggregate data, a proper policy analysis should rely more on disaggregated data.

The results from the discrete-time hazard model indicate that a decrease in the MLDA from 21 years to 18, 19, or 20 years significantly increases the probability of first pregnancy for 15-20 year-old black women. Specifically, a decrease in the MLDA increases the probability of a first pregnancy by 3.9 percentage points. A qualitatively and quantitatively similar result for 15-17 year-old blacks indicates that the effect observed for 15-20 year-old group is primarily due to the effect on 15-17 year olds. This finding is, in spirit, similar to results reported for black women in Dee (2001). However, unlike Dee, I do not find evidence that the MLDA policy affect birth rates among black teens (or abortion rates for that matter). I also find that a decrease in the MLDA is associated with 8.8 percentage point decrease in the probability of pregnancy for 15-20 year-old Hispanics. The even larger effect is observed for 18-20 year-old Hispanic women. Pregnancy rates among white women of any age seem to be unaffected by changes in the MLDA. The observed differentiated response across race-age groups might reflect cultural and behavioral differences or other unobservable factors. 
I do not find strong evidence of a compositional change in the pool of women who become pregnant due to changes in the MLDA as suggested by Fertig and Watson (2009), but I do find such change due to changes in the legal eligibility status. For 18-20 year-old white women, becoming legally eligible to drink at the time of first pregnancy increases the probability of live birth by 29.1 percentage points and decreases the probability of abortion by 14.7 percentage points. Although the effects of a decrease in the MLDA on the probabilities of pregnancy outcome are similar in terms of the sign, the estimates are weaker in the statistical sense. The latter result is expected as changes in the MLDA firstly are likely to alter drinking behavior of those teens who are actually affected by the change and to a lesser extent those who are still not legally eligible to drink even after a reduction in the MLDA. The compositional change perhaps could be caused by a change in the pattern of alcohol consumption behavior among white and Hispanic women, namely the place where the alcohol is consumed and the intensity of alcohol consumption that are triggered by changes in eligibility status rather than the MLDA per se. Given that the results differ across considered outcomes, models, and races, more research is needed to identify the mechanisms through which alcohol consumption restrictions affect teen childbearing rates.

\section{References}

Ai, C., Norton E.C., 2003. Interaction terms in logit and probit models. Econ Lett 80, 123-129

Allen, D.N, Sprenkel, D.G., Vitale, P.A., 1994. Reactance theory and alcohol consumption laws: Further confirmation among collegiate alcohol consumers. J Stud Alcohol 55, 34-40

Allison, P.D., 1982. Discrete-time methods for the analysis of event histories. Sociol Methodol 13, 61-98

Allison, P.D., 1999. Comparing logit and probit coefficients across groups. Sociol Method Res 28(2), 186-208

Blank, R.M., George, C.C., London, R.A., 1996. State abortion rates: the impact of policies, providers, politics, demographics and economic environment, J Health Econ 15, 513-553 
Bond, J.R., Johnson, C.A., 1982. Implementing a Permissive Policy: Hospital Abortion Services after Roe v. Wade. Am J Polit Sci 26(1), 1-24

Box-Steffensmeier, J., Jones, B.S., 2004. Event History Modeling: A Guide for Social Scientists. Cambridge, UK: Cambridge University Press

Carpenter, C., Dobkin, C., 2009. The effect of alcohol access on consumption and mortality: Regression Discontinuity evidence from the minimum drinking age. Am Econ J: Appl Econ 1(1), 164-182

Coate, D., Grossman, M., 1988. Effects of alcoholic beverage prices and legal drinking ages on youth alcohol use. J Law Econ 31(1), 145-171

Dee, T.S., 1999. State alcohol policies, teen drinking and traffic fatalities. J Public Econ 72, 289-315

Dee, T.S., 2001. The Effects of Minimum Legal Drinking Ages on Teen Childbearing. J Hum Resour 36(4), Special Issue on Early Results from the National Longitudinal Survey of Youth, 1997 Cohort, 823-838

Dee, T.S., Evans, W.N., 2003. Teen drinking and educational attainment: Evidence from two-sample instrumental variables estimates. J Labor Econ 21(1): 178-209

Donovan, C., McEwan, R., 1995. A Review of the Literature examining the relationship between Alcohol Use and HIV-related Sexual Risk-taking in Young People. Addict 90, 319-328

Fertig, A.R., Watson, T., 2009. Minimum drinking age laws and infant health outcomes. J Health Econ 28, 737-747

Figlio, D.N., 1995. The Effect of Drinking Age Laws and Alcohol-Related Crashes:

Time-Series Evidence from Wisconsin. J Policy Anal Manag 14(4), 555-566

Finer, L.B., Henshaw, S.K., 2006. Disparities in rates of unintended pregnancy in the United States, 1994 and 2002. Perspect Sex Reprod Health, 38(2), 90-96

Fletcher, J., Wolfe, B.L., 2008. Education and Labor Market Consequences of Teenage Childbearing: Evidence Using the Timing of Pregnancy Outcomes and Community Fixed Effects. NBER Working paper No.13847

Gold, R.B., 2003. Lessons from before Roe: Will past be prologue? Guttmacher Report on Public Policy, March, 8-11

Greene, W., 1998. Gender economics courses in liberal arts colleges: further results. J Econ Educ 29(4), 291-300

Greenberger, M.D., Connor, K., 1991. Parental Notice and Consent for Abortion: Out of Step with Family Law Principles and Policies. Fam Plan Perspect 23(1), 31-35

Grossman, M., Chaloupka, F.J., Saffer H., Laixuthai, A., 1994. Effects of alcohol price policy on youth: A summary of economic research. J Res Adolesc, 4(2), 347-364 
Grossman, M., Markowitz, S., 2005. I Did What Last Night? Adolescent Risky Sexual Behaviors and Substance Use. East Econ J 3(3), 383-405

Haas-Wilson, D., 1996. The economic impact of state abortion restrictions on minors' demand for abortions. J Hum Resour 31(1), 140-158

O’Hare, T., 2005. Risky sex and drinking contexts in freshman first offenders. Addict Behav 30(9), 585-588

Hingson, R. W., Strunin, L., Berlin, B. M., Heeren T., 1990. Beliefs about AIDS, use of alcohol and drugs, and unprotected sex among Massachusetts adolescents. Am J Public Health 80, 295-299

Jones, E.F., Darroch Forrest, J., 1989. Contraceptive failure in the United States: Revised estimates from the 1982 National Survey of Family Growth. Fam Plan Perspect 21, 103109

Jones, E.F., Darroch Forrest, J., 1992. Underreporting of abortion in Surveys of U.S. women: 1976 to 1988. Demography 29(1), 113-126

Kaestner, R., 2000. A note on the effect of minimum drinking age laws on youth alcohol consumption. Contemp Econ Policy 18(3), 315-325

Leigh, B., Stall, R., 1993. Substance use and risky sexual behavior for exposure to HIV, issues in methodology, interpretation and prevention. Am Psychol, 1035-1044

Long, J.S., 1997. Regression models for categorical and limited dependent variables. Advanced quantitative techniques in the social sciences. Sage Publication

Long, J.S., 2009. Group comparisons in logit and probit using predicted probabilities. Working paper draft 2009-06-25. Retrieved on September 15, 2009

O’Malley, P.M., Wagenaar, A.C., 1990. Minimum drinking age laws: effects on American youth 1976-1987. Monitoring the Future Occasional Paper Series 28

Markowitz, S., Kaestner R., Grossman, M., 2005. An Investigation of the Effects of Alcohol consumption and Alcohol Policies on Youth Risky Sexual Behaviors. Am Econ Rev 95(2), 263-266

Merz, J.F., Jackson, C.A., Klerman, J.A., 1995. A Review of Abortion Policy: Legality, Medicaid Funding, and Parental Involvement, 1967-1994. Women's Rights Law Reporter, Winter 1995, 1-61

Naimi, T.S., Lipscomb, L.E., Brewer R.D., Gilbert, B.C., 2003. Binge Drinking in the Preconception Period and the Risk of Unintended Pregnancy: Implications for Women and Their Children. Pediatrics 111, 1136-1141

New, M.J., 2004. Analyzing the Effects of State Legislation on the Incidence of Abortion During the 1990s. The Heritage Center for Data Analysis Report \#04-01. Retrieved on August 2, 2009

Rashad, I., Kaestner, R., 2004. Teenage sex, drugs and alcohol use: problems identifying the cause of risky behavior. J Health Econ 23, 493-503 
Rees, D.I., Argys, L.M., Averett, S.L., 2001. New evidence on the relationship between substance use and adolescent sexual behavior. J Health Econ 20, 835-845

Sen, B., 2003. Can Beer Taxes Affect Teen Pregnancy? Evidence Based on Teen Abortion Rates and Birth Rates. South Econ J 70(2), 328-343

Singer, J.D., Willett, J.B., 2003. Applied longitudinal data analysis: Modeling change and event occurrence. Oxford University Press

Udry, J.R., Gaughan, M., Schwingl, P.J, van den Berg, B.J., 1996. A Medical Record Linkage Analysis of Abortion Underreporting. Fam Plan Perspect 28(5), 228-231

Wagenaar, A.C., 1981. Legal minimum drinking age changes in the United States, 19701981. Alcohol Health Res World 6(2), 21-26

Wagenaar, A.C., Salois, M.J., Komro, K.A., 2009. Effects of beverage alcohol price and tax levels on drinking: a meta-analysis of 1003 estimates from 112 studies. Addict 104, $179-190$

Wagenaar, A.C., Toomey, T.L., 2002. Effects of minimum drinking age laws: review and analyses of the literature from 1960 to 2000. J Stud Alcohol Suppl 63(2), 206-226

Wechsler, H., Kuo, M., Lee, H., Dowdall, G.W., 2000. Environmental correlates of underage alcohol use and related problems of college students. Am J Preventive Med 19(1), 24-29

Wendel, H.F., Wendel, C.S., 2004. Vital Statistics of the United States: Births, Life Expectancy, Deaths, and Selected Health Data. Bernan Press

Zelnik, M., Shah, F.K., 1983. First intercourse among young Americans. Fam Plan Perspect 15(2), 64-70 
Table 1: Timing of the first pregnancy and its outcome aggregated by years of age for 15-20 and 21-23 year-old women

\begin{tabular}{|c|c|c|c|c|c|c|c|c|}
\hline & & & & & \multicolumn{2}{|c|}{ Hazard function of $1^{\text {st }}$ pregnancy } & \multicolumn{2}{|c|}{ Survivor function of $1^{\text {st }}$ pregnancy } \\
\hline $\begin{array}{l}\text { Age in } \\
\text { years }\end{array}$ & $\begin{array}{l}\text { Females } \\
\text { at risk }\end{array}$ & $\begin{array}{l}\text { Had the } 1^{\text {st }} \\
\text { pregnancy }\end{array}$ & $\begin{array}{l}\text { Had the }^{\text {st }} \\
\text { pregnancy } \\
\text { and gave } \\
\text { birth }\end{array}$ & $\begin{array}{l}\text { Had the } 1^{\text {st }} \\
\text { pregnancy } \\
\text { and } \\
\text { terminated }\end{array}$ & $\begin{array}{c}\text { Estimated hazard } \\
\text { probability }\end{array}$ & $\begin{array}{l}\text { Standard } \\
\text { error }\end{array}$ & $\begin{array}{l}\text { Estimated survival } \\
\text { probability }\end{array}$ & $\begin{array}{l}\text { Standard } \\
\text { error }\end{array}$ \\
\hline 15 & 4690 & 222 & 175 & 36 & 0.047 & 0.003 & 0.953 & 0.003 \\
\hline 16 & 4468 & 328 & 260 & 48 & 0.073 & 0.004 & 0.883 & 0.005 \\
\hline 17 & 4140 & 353 & 265 & 63 & 0.085 & 0.004 & 0.808 & 0.006 \\
\hline 18 & 3787 & 406 & 296 & 64 & 0.107 & 0.005 & 0.721 & 0.007 \\
\hline 19 & 3381 & 389 & 293 & 61 & 0.115 & 0.005 & 0.638 & 0.007 \\
\hline 20 & 2992 & 274 & 187 & 43 & 0.092 & 0.005 & 0.580 & 0.007 \\
\hline \multicolumn{9}{|c|}{ Older women: Control group } \\
\hline 21 & 2718 & 264 & 201 & 30 & 0.097 & 0.006 & 0.523 & 0.007 \\
\hline 22 & 2454 & 234 & 189 & 28 & 0.095 & 0.006 & 0.473 & 0.007 \\
\hline 23 & 2220 & 216 & 162 & 28 & 0.097 & 0.006 & 0.427 & 0.007 \\
\hline
\end{tabular}

Note. - Hazard and survivor functions for each outcome (i.e, birth and abortion) are available on request. 
Table 2: Descriptive statistics for 15-20 year-old women, 1972-1985

\begin{tabular}{|c|c|c|c|c|}
\hline \multirow{2}{*}{ Variable } & \multirow{2}{*}{ Mean } & \multirow{2}{*}{ SD } & \multicolumn{2}{|c|}{ Observations } \\
\hline & & & person-month & person \\
\hline \multicolumn{5}{|l|}{ Time variant variables } \\
\hline \multicolumn{5}{|l|}{ Legally eligible to drink } \\
\hline (adjusted for the grandfather clause) & 0.32 & 0.47 & 333,637 & 4,685 \\
\hline MLDA is 18,19 or 20 years & 0.71 & 0.45 & 333,637 & 4,685 \\
\hline Currently married & 0.11 & 0.31 & 337,680 & 4,690 \\
\hline Previously been married & 0.01 & 0.11 & 337,680 & 4,690 \\
\hline Never been married & 0.88 & 0.32 & 337,680 & 4,690 \\
\hline Enforced parental notification/consent law for abortion & 0.02 & 0.12 & 334,267 & 4,690 \\
\hline Contraception use before $1^{\text {st }}$ pregnancy & 0.44 & 0.50 & 231,552 & 3,216 \\
\hline \multicolumn{5}{|l|}{ Time invariant variables } \\
\hline Black & 0.29 & 0.45 & 337,680 & 4,690 \\
\hline Hispanic & 0.20 & 0.40 & 337,680 & 4,690 \\
\hline White & 0.51 & 0.50 & 337,680 & 4,690 \\
\hline Raised in Baptist family & 0.30 & 0.46 & 336,816 & 4,678 \\
\hline Raised in other religion & 0.31 & 0.46 & 336,816 & 4,678 \\
\hline Raised as Atheist & 0.03 & 0.17 & 336,816 & 4,678 \\
\hline Raised in Catholic family & 0.36 & 0.48 & 336,816 & 4,678 \\
\hline AFQT score below mean & 0.56 & 0.50 & 322,920 & 4,485 \\
\hline Two-parents are in the household at age 14 & 0.68 & 0.46 & 337,032 & 4,681 \\
\hline Mother's education (years) & 10.76 & 3.25 & 319,176 & 4,433 \\
\hline Father's education (years) & 10.88 & 4.01 & 287,856 & 3,998 \\
\hline Presence of older siblings & 0.78 & 0.41 & 317,664 & 4,412 \\
\hline
\end{tabular}

Note. - Data sources for the state MLDA: Wagenaar (1981), O'Malley and Wagenaar (1990), and the National Highway Traffic Safety Administration website. If for some time period a woman was outside of the USA then eligibility restriction variables and state dummies were assigned a missing value for that time period. Data sources for parental notification laws: Merz et al. (1995), Haas-Wilson (1996), Greenberger and Connor (1991), New (2004), and NARAL website. 
Table 3: Predicted probability of first pregnancy and conditional probabilities of birth and abortion, by race-age groups

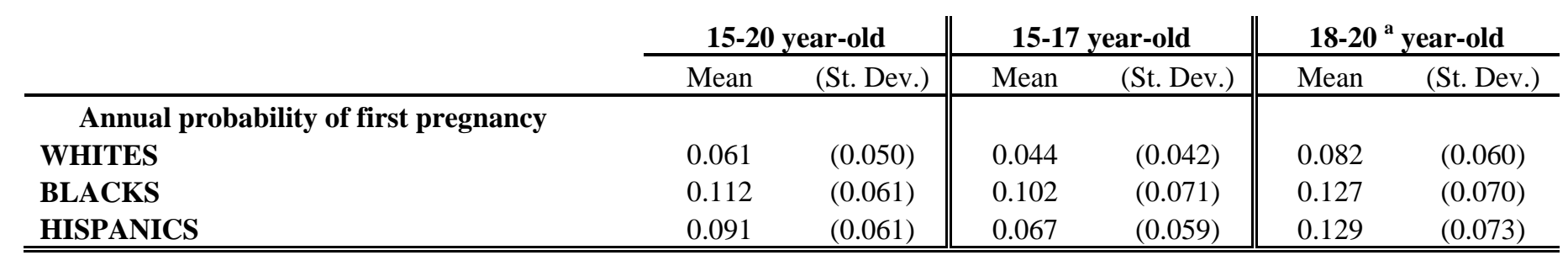

\begin{tabular}{|c|c|c|c|c|c|c|}
\hline \multicolumn{7}{|c|}{ Predicted probability of birth (conditional on $1^{\text {st }}$ pregnancy) } \\
\hline WHITES & 0.648 & $(0.204)$ & 0.658 & $(0.234)$ & 0.626 & $(0.216)$ \\
\hline BLACKS & 0.806 & (0.168) & 0.814 & $(0.200)$ & 0.783 & $(0.201)$ \\
\hline HISPANICS & 0.747 & $(0.199)$ & 0.768 & $(0.304)$ & 0.717 & $(0.240)$ \\
\hline \multicolumn{7}{|c|}{ Predicted probability of abortion (conditional on $1^{\text {st }}$ pregnancy) } \\
\hline WHITES & 0.250 & $(0.201)$ & 0.299 & $(0.240)$ & 0.246 & $(0.210)$ \\
\hline BLACKS & 0.140 & $(0.166)$ & 0.174 & $(0.233)$ & 0.160 & $(0.198)$ \\
\hline HISPANICS & 0.170 & (0.188) & 0.200 & $(0.304)$ & 0.169 & (0.243) \\
\hline
\end{tabular}

Note: - The annual predicted probability of first pregnancy is calculated using monthly predicted probabilities. ${ }^{a}$ Results are reported for the model with the MLDA dummy; the predicted probabilities for the model with the eligibility dummy are numerically very similar. 
Table 4: The average effect of a DECREASE in the MLDA on the probability of first pregnancy, by race-age groups

\begin{tabular}{|c|c|c|c|c|c|c|c|c|c|c|c|c|}
\hline \multirow[b]{3}{*}{$\begin{array}{l}\text { Annual average } \\
\text { predicted probability } \\
\text { of } 1^{\text {st }} \text { pregnancy if } \\
\text { MLDA is } \mathbf{2 1}\end{array}$} & \multicolumn{3}{|c|}{ 15-20 year-old women } & \multicolumn{3}{|c|}{ 15-17 year-old women } & \multicolumn{3}{|c|}{ 18-20 year-old women } & \multicolumn{3}{|c|}{ 21-23 year-old women } \\
\hline & Whites & Blacks & Hispanics & Whites & Blacks & Hispanics & Whites & Blacks & Hispanics & Whites & Blacks & Hispanics \\
\hline & $\begin{array}{l}0.064 \\
(0.01)\end{array}$ & $\begin{array}{l}0.084 \\
(0.01)\end{array}$ & $\begin{array}{l}0.153 \\
(0.04)\end{array}$ & $\begin{array}{l}0.052 \\
(0.01)\end{array}$ & $\begin{array}{l}0.074 \\
(0.02)\end{array}$ & $\begin{array}{l}0.070 \\
(0.03)\end{array}$ & $\begin{array}{l}0.088 \\
(0.02)\end{array}$ & $\begin{array}{l}0.109 \\
(0.04)\end{array}$ & $\begin{array}{l}0.360 \\
(0.09)\end{array}$ & $\begin{array}{l}0.082 \\
(0.01)\end{array}$ & $\begin{array}{l}0.133 \\
(0.03)\end{array}$ & $\begin{array}{l}0.119 \\
(0.02)\end{array}$ \\
\hline $\begin{array}{l}\text { Annual average } \\
\text { predicted probability } \\
\text { of } 1^{\text {st }} \text { pregnancy if } \\
\text { MLDA is } \\
\mathbf{1 8 , 1 9} \text { or } \mathbf{2 0}\end{array}$ & $(0.00)$ & $(0.01)$ & $(0.01)$ & $\begin{array}{l}0.042 \\
(0.00)\end{array}$ & $\begin{array}{l}0.114 \\
(0.01)\end{array}$ & (0.09) & $\begin{array}{l}0.079 \\
(0.01)\end{array}$ & $\begin{array}{l}0.133 \\
(0.02)\end{array}$ & $\begin{array}{l}0.070 \\
(0.01)\end{array}$ & $\begin{array}{l}0.080 \\
(0.01)\end{array}$ & $\begin{array}{l}0.103 \\
(0.01)\end{array}$ & $\begin{array}{l}0.119 \\
(0.02)\end{array}$ \\
\hline $\begin{array}{l}\text { Discrete change } \\
\text { due to a decrease } \\
\text { in MLDA }(\bar{\Delta})\end{array}$ & $\begin{array}{r}-\mathbf{0 . 0 0 3} \\
(0.01)\end{array}$ & $\begin{array}{l}\mathbf{0 . 0 3 9}^{+} \\
(0.02)\end{array}$ & $\begin{array}{c}-\mathbf{0 . 0 8 8}^{+} \\
(0.05)\end{array}$ & $\begin{array}{r}-\mathbf{0 . 0 1 0} \\
(0.01)\end{array}$ & $\begin{array}{l}\mathbf{0 . 0 4 0}^{+} \\
(0.02)\end{array}$ & $\begin{array}{l}-\mathbf{0 . 0 0 5} \\
(0.11)\end{array}$ & $\begin{array}{r}-\mathbf{0 . 0 1 0} \\
(0.02)\end{array}$ & $\begin{array}{l}\mathbf{0 . 0 2 4} \\
(0.05)\end{array}$ & $\begin{array}{c}-\mathbf{0 . 2 9 0 *} \\
(0.10)\end{array}$ & $\begin{array}{l}-\mathbf{0 . 0 0 1} \\
(0.02)\end{array}$ & $\begin{array}{r}-\mathbf{0 . 0 3 1} \\
(0.03)\end{array}$ & $\begin{array}{l}\mathbf{0 . 0 0 0} \\
(0.04)\end{array}$ \\
\hline \# of observations & 133,600 & 63,846 & 44,716 & 73,608 & 37,694 & 25,285 & 59,695 & 25,614 & 18,348 & 46,104 & 17,262 & 12,544 \\
\hline
\end{tabular}

Note. - Bootstrap standard errors are in parenthesis. ${ }^{* *}$ significant at $1 \% ;{ }^{*}$ significant at $5 \% ;{ }^{+}$significant at $10 \%$. 
Table 5: The average effect of a DECREASE in the MLDA on the conditional probability of birth and the conditional probability of abortion, by race-age group

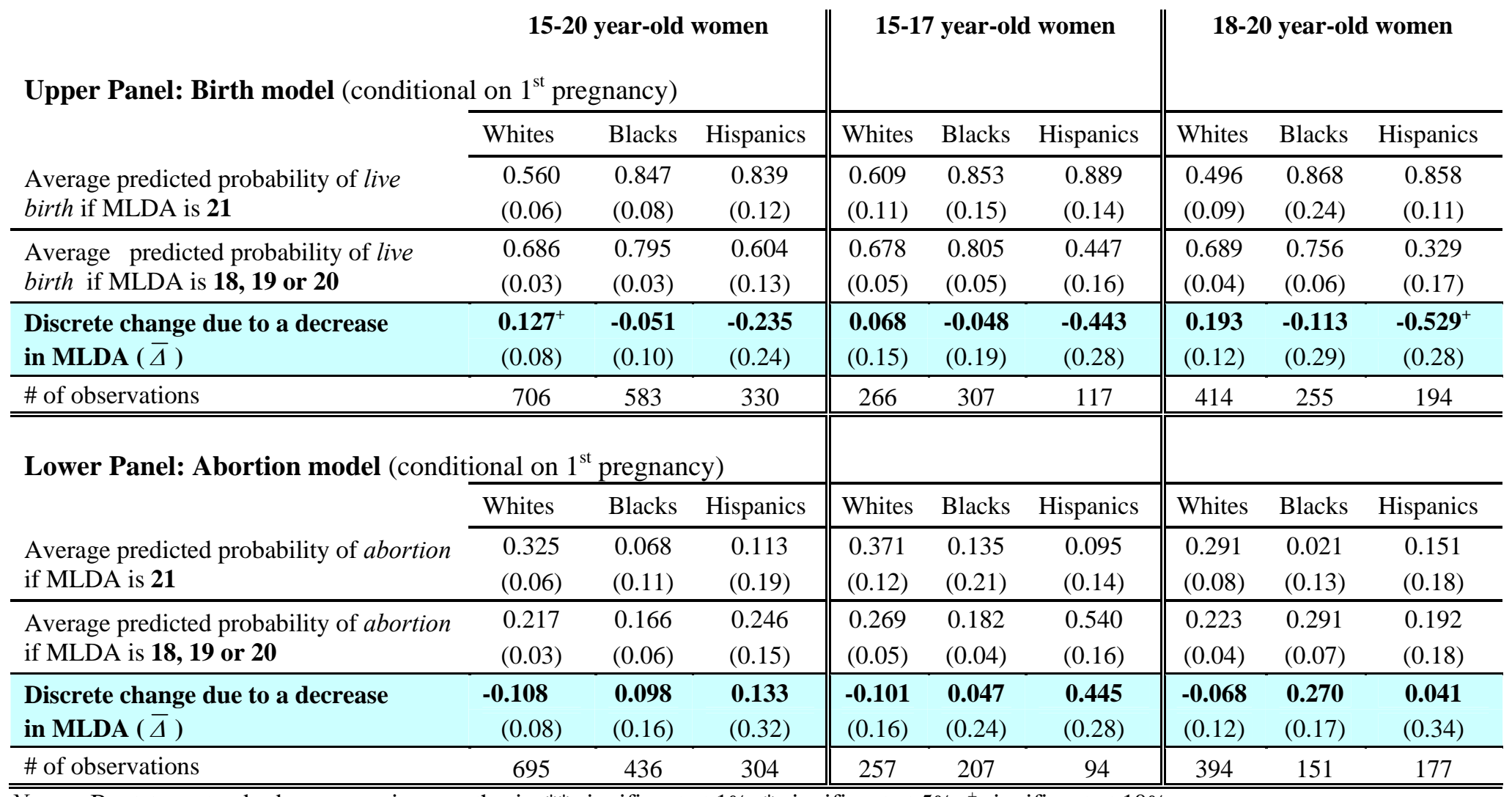

Note. - Bootstrap standard errors are in parenthesis. ${ }^{* *}$ significant at $1 \%$; ${ }^{*}$ significant at $5 \%{ }^{+}{ }^{+}$significant at $10 \%$. 
Table 6: The average effect of BECOMING LEGALLY ELIGIBLE to drink on the probability of first pregnancy and the conditional probabilities of birth and abortion, 1820 year-old women

\section{Upper Panel: Pregnancy model}

\begin{tabular}{lccc} 
& WHITES & BLACKS & HISPANICS \\
\hline Annual average predicted probability of 1st pregnancy & 0.091 & 0.151 & 0.153 \\
if cannot legally drink & $(0.01)$ & $(0.02)$ & $(0.02)$ \\
\hline Annual average predicted probability of 1st pregnancy & 0.076 & 0.119 & 0.108 \\
if can legally drink & $(0.01)$ & $(0.01)$ & $(0.02)$ \\
\hline Discrete change due to becoming legally & $-\mathbf{0 . 0 1 4}$ & $\mathbf{- 0 . 0 3 2}$ & $\mathbf{- 0 . 0 4 5}$ \\
eligible to drink $(\bar{\Delta})$ & $(0.02)$ & $(0.03)$ & $(0.04)$ \\
\hline \# of observations & 59,695 & 25,614 & 18,348 \\
\hline \hline
\end{tabular}

Middle Panel: Birth model (conditional on $1^{\text {st }}$ pregnancy)

\begin{tabular}{lccc} 
& WHITES & BLACKS & HISPANICS \\
\hline Average predicted probability of live birth & 0.446 & 0.798 & 0.864 \\
if cannot legally drink & $(0.06)$ & $(0.09)$ & $(0.02)$ \\
\hline Average predicted probability of live birth & 0.737 & 0.777 & 0.311 \\
if can legally drink & $(0.03)$ & $(0.04)$ & $(0.03)$ \\
\hline Discrete change due to becoming legally & $\mathbf{0 . 2 9 1 * *}$ & $\mathbf{- 0 . 0 2 1}$ & $\mathbf{- 0 . 5 5 2 ^ { * * }}$ \\
eligible to drink $(\bar{\Delta})$ & $(0.08)$ & $(0.12)$ & $(0.03)$ \\
\hline \# of observations & 414 & 255 & 194 \\
\hline \hline
\end{tabular}

Lower Panel: Abortion model (conditional on $1^{\text {st }}$ pregnancy)

\begin{tabular}{lccc} 
& WHITES & BLACKS & HISPANICS \\
\hline Average predicted probability of abortion & 0.335 & 0.085 & 0.068 \\
if cannot legally drink & $(0.06)$ & $(0.13)$ & $(0.03)$ \\
\hline Average predicted probability of abortion & 0.190 & 0.186 & 0.602 \\
$\quad$ if can legally drink & $(0.03)$ & $(0.07)$ & $(0.08)$ \\
\hline Discrete change due to becoming legally & $\mathbf{- 0 . 1 4 7 ^ { + }}$ & $\mathbf{0 . 1 0 1}$ & $\mathbf{0 . 5 3 4 ^ { * * }}$ \\
eligible to drink $(\bar{\Delta})$ & $(0.09)$ & $(0.18)$ & $(0.10)$ \\
\hline \#of observations & 394 & 151 & 177 \\
\hline \hline Note. - Bootstrap standard errors are in parenthesis. ${ }^{* *}$ significant at 1\%; * significant at 5\%; ${ }^{+}$significant \\
at $10 \%$
\end{tabular}




\section{Appendix A}

Table A-1: State MLDA for beer, 1970-1988

\begin{tabular}{|c|c|c|}
\hline State & $\begin{array}{l}\text { MLDA on } \\
1 / 1 / 1970\end{array}$ & Changes in MLDA in the period 1/1/1970 -1/1/1988 \\
\hline Alabama & $1 / 1 / 1970-21$ & $7 / 1 / 1975-19 ; 10 / 1 / 1985-21^{\mathrm{gc}}$ \\
\hline Alaska & $1 / 1 / 1970-21$ & 9/1/1970 - 19; 11/1/1984- 21 \\
\hline Arizona & $1 / 1 / 1970-21$ & $8 / 1 / 1972-19 ; 1 / 1 / 1985-21^{g c}$ \\
\hline Colorado & $1 / 1 / 1970-18$ & $7 / 1 / 1987-21$ \\
\hline Connecticut & $1 / 1 / 1970-21$ & 10/1/1972 - 18; 7/1/1982 - 19; 10/1/1983 - 20; 9/1/1985 - 21 $1^{\mathrm{gc}}$ \\
\hline Delaware & $1 / 1 / 1970-21$ & $7 / 1 / 1972-20 ; 1 / 1 / 1984-21^{\mathrm{gc}}$ \\
\hline DC & $1 / 1 / 1970-18$ & $9 / 1 / 1986-21^{g c}$ \\
\hline Florida & $1 / 1 / 1970-21$ & 7/1/1973 - 18; 10/1/1980 - 19; 7/1/1985 - 21 ${ }^{\mathrm{gc}}$ \\
\hline Georgia & $1 / 1 / 1970-21$ & 7/1/1972 - 18; 9/1/1980 - 19; 9/1/1985 - 20; 9/1/1986 - 21 \\
\hline Hawaii & $1 / 1 / 1970-20$ & 3/1/1972 - 18; 10/1/1986 - 21 \\
\hline Iowa & $1 / 1 / 1970-21$ & $4 / 1 / 1972-19 ; 7 / 1 / 1973-18 ; 7 / 1 / 1976-19^{g c} ; 9 / 1 / 1986-21^{g c}$ \\
\hline Idaho & $1 / 1 / 1970-20$ & 7/1/1972 - 19; 4/1/1987 - 21 \\
\hline Illinois & $1 / 1 / 1970-21$ & 9/1/1973 - 19; 1/1/1980-21 \\
\hline Kansas & $1 / 1 / 1970-18$ & $7 / 1 / 1985-21^{\mathrm{gc}}$ \\
\hline Louisiana & $1 / 1 / 1970-18$ & $3 / 1 / 1987-21$ \\
\hline Maine & $1 / 1 / 1970-20$ & 6/1/1972 - 18; 10/1/1977 - 20; 7/1/1985 - 21 $1^{\mathrm{gc}}$ \\
\hline Maryland & $1 / 1 / 1970-21$ & 7/1/1974-18; 7/1/1982-21 \\
\hline Massachusetts & $1 / 1 / 1970-21$ & $3 / 1 / 1973-18 ; 4 / 1 / 1979-20 ; 6 / 1 / 1985-21^{g c}$ \\
\hline Michigan & $1 / 1 / 1970-21$ & 1/1/1972 - 18; 12/1/1978 - 21 \\
\hline Minnesota & $1 / 1 / 1970-21$ & 6/1/1973 - 18; 9/1/1979 - 19 $9^{\mathrm{gc}} ; 9 / 1 / 1986-21^{\mathrm{gc}}$ \\
\hline Mississippi & $1 / 1 / 1970-18$ & 10/1/1986-21 \\
\hline Montana & $1 / 1 / 1970-21$ & 7/1/1971 - 19; 7/1/1973 - 18; 1/1/1979 - 19; 4/1/1987 - 21 \\
\hline Nebraska & $1 / 1 / 1970-20$ & $6 / 1 / 1972-19 ; 7 / 1 / 1980-20^{\mathrm{gc}} ; 1 / 1 / 1985-21^{\mathrm{gc}}$ \\
\hline New Hampshire & $1 / 1 / 1970-21$ & $6 / 1 / 1973-18 ; 5 / 1 / 1979-20 ; 6 / 1 / 1985-21^{\mathrm{gc}}$ \\
\hline New Jersey & $1 / 1 / 1970-21$ & $1 / 1 / 1973-18 ; 1 / 1 / 1980-19^{\mathrm{gc}} ; 1 / 1 / 1983-21^{\mathrm{gc}}$ \\
\hline New York & $1 / 1 / 1970-18$ & 12/1/1982-19; 12/1/1985-21 \\
\hline North Carolina & $1 / 1 / 1970-18$ & 10/1/1983 - 19; 9/1/1986 - 21 \\
\hline Ohio & $1 / 1 / 1970-18$ & $8 / 1 / 1982-19 ; 7 / 1 / 1987-21^{\mathrm{gc}}$ \\
\hline Oklahoma & $1 / 1 / 1970-18$ & $9 / 1 / 1983-21$ \\
\hline Rhode Island & $1 / 1 / 1970-21$ & $3 / 1 / 1972-18 ; 7 / 1 / 1980-19 ; 7 / 1 / 1981-20 ; 7 / 1 / 1984-21$ \\
\hline South Carolina & $1 / 1 / 1970-18$ & 1/1/1984 - 19; 1/1/1985 - 20; 9/1/1986 - 21 \\
\hline South Dakota & $1 / 1 / 1970-19$ & 7/1/1972 - 18; 7/1/1984 - 19; 4/1/1988 - 21 \\
\hline Tennessee & $1 / 1 / 1970-21$ & $5 / 1 / 1971-18 ; 6 / 1 / 1979-19 ; 8 / 1 / 1984-21^{g c}$ \\
\hline Texas & $1 / 1 / 1970-21$ & 8/1/1973 - 18; 9/1/1981 - 19; 9/1/1986 - 21 \\
\hline Vermont & $1 / 1 / 1970-21$ & $7 / 1 / 1971-18 ; 7 / 1 / 1986-21^{\mathrm{gc}}$ \\
\hline Virginia & $1 / 1 / 1970-21$ & 7/1/1974-18; 7/1/1981 - 19; 7/1/1985-21 ${ }^{\mathrm{gc}}$ \\
\hline West Virginia & $1 / 1 / 1970-18$ & 7/1/1983 - 19; 7/1/1986-21 \\
\hline Wisconsin & $1 / 1 / 1970-18$ & $7 / 1 / 1984-19 ; 9 / 1 / 1986-21^{\mathrm{gc}}$ \\
\hline Wyoming & $1 / 1 / 1970-21$ & $5 / 1 / 1973-19 ; 7 / 1 / 1988-21$ \\
\hline
\end{tabular}

Note. - MLDA in Arkansas, California, Indiana, Kentucky, Missouri, Nevada, New Mexico, North Dakota, Oregon, Pennsylvania, Utah, and Washington was 21 years during 1/1/1970-1/1/1988. Source: Wagenaar (1981), O’Malley and Wagenaar (1990), and the National highway traffic safety administration online reports.

gc Indicates that the law change includes a "grandfather clause". 


\section{Appendix B: Analysis of aggregated data}

An initial simple test of whether changes in the MLDA affect teen childbearing can be performed using a difference-in-difference (DID) estimation and state-level data.

I constructed annual state level pregnancy rates for the 15-19 and 25-29 age groups as the sum of births, fetal deaths, and legally induced abortions to women in that age group, for each year in the period 1973 through 1988 using data available from the Vital Statistics Reports and Abortion Surveillance Reports. ${ }^{15}$ The number of births in a given year does not precisely reflect the number of pregnancies conceived in that year. Given that pregnancy normally lasts for nine months, only babies conceived in the first quarter of the year will be born in that same year; those conceived later will be born in the next year. Hence, number of pregnancies can be computed as:

$$
\text { Pregnancies }_{g s t}=1 / 4 \text { Birth }_{g s t}+3 / 4 \text { Births }_{g s t+1}+\text { Fetal death } s_{g s t}+\text { Abortions }_{g s t} \text {, }
$$

where $g$ stands for the age group, $s$ indexes states and $t$ indexes years. ${ }^{16}$

Estimates based on these pregnancy rates are likely to be underestimated due to the lack of uniform reporting requirements of fetal deaths and abortions across states. Most states require reporting of fetal death at gestations of 20 weeks or more. Thus, the reported number of fetal deaths does not include deaths that occurred prior to 20 weeks of gestation for majority of states. Some states do not report abortions by age groups or do not report them at all or on a continuous basis. ${ }^{17}$ Therefore, the constructed panel contains numerous missing values for abortion rates as well as pregnancy rates (193 missing observations out of a possible 765 in each age group). In addition, abortion data are not available by state, year, age group, and race. Therefore for analysis of abortion and pregnancy rates, unlike Dee (2001), I cannot estimate separate DID models for each race.

Average fertility rates for 15-19 and 25-29 year-old women are reported in Table B-1. It appears that for all age groups fertility rates are higher in states with the MLDA

\footnotetext{
${ }^{15}$ The other age group available in the aggregate data is women 20-24 years old. Results are not highly sensitive to the choice of the control group. For example, when using 20-24 as a control group, the estimates of interest have the same sign and lack statistical significance in all models. Since differences are subtle, I discuss only results for 25-29 control group.

${ }^{16}$ Using the alternative formula: Pregnancies ${ }_{\mathrm{gst}}=$ Births $_{\mathrm{gst}+1}+$ Fetal deaths $_{\mathrm{gst}}+$ Abortions $_{\mathrm{gst}} \mathrm{did}$ not significantly alter pregnancy rates or the DID model estimates.

${ }^{17}$ For details on abortion reporting see CDC/NCHS Handbook on the Reporting of Induced Termination of Pregnancy, http://www.cdc.gov/nchs/data/misc/hb_itop.pdf.
} 
set to 18 or 19 years. However, most of these cross-state differences are statistically significant only for 15-19 age group. For example, teen pregnancy rate in states with a low MLDA is about 5 pregnancies per 1,000 teens higher than in states with the MLDA set to 20 or 21. A smaller difference is observed for teen birth rate (about 2 births per 1,000 teens). The question is whether these differences will be observed after controlling for state socio-economic characteristics.

The baseline model for pregnancy, birth, and abortion is given by

$$
\begin{gathered}
\ln \left(Y_{g s t}\right)=\beta_{0}+\beta_{1} \text { TEENS }_{s t}+\beta_{2} \text { MLDA_18or19 } A_{s t}+\beta_{3}(\text { TEENS*MLDA_18or19 })_{s t} \\
+\gamma X_{g s t}+\lambda_{s}+\tau_{t}+\varepsilon_{g s t},
\end{gathered}
$$

where $g$ indexes age groups, $s$ indexes states and $t$ indexes years 1973 through 1988.

The dependent variable $Y_{g s t}$ is pregnancy rate or birth rate or abortion rate per 1,000 women in the corresponding age group in a state-year. A dummy variable, TEENS, separates the treatment group - women 15-19 years old - and the control group - women 25-29 years. The variable $M L D A \_18$ or 19 indicates whether the prevailing MLDA for beer in state $s$ at time $t$ is set to 18 or 19 years. The estimate of the effect of the MLDA set to 18 or 19 on teen childbearing rate is given by $\beta_{3}$. If relaxing MLDA restrictions triggers risky sexual behavior then pregnancy, birth, and abortion rates for 15-19 year-old women would increase relative to the control group in response to a low MLDA, implying a positive $\beta_{3}$.

The vector $X_{g s t}$ includes the state unemployment rate, percentage of black population in the state, per gallon state beer tax, per capita personal income, the maximum Aid to Families with Dependent Children (AFDC) benefit level for a family of four, controls for the presence of Medicaid funding restrictions for abortion, enforced parental involvement laws for minors, and measures that attempt to control for the “border hopping” phenomena. ${ }^{18}$ Descriptive statistics, description, and corresponding data sources of the variables included in the model are reported in Table B-2.

Similar to the abortion demand literature I include the number of abortion providers, which is an endogenous variable, in equation (B2). Following the approach of Bank et al. (1996), I use a standard two-stage least squares procedure to correct for

\footnotetext{
${ }^{18}$ The "border hopping" refers to a practice where teens attempt to avoid restrictions in their home state by obtaining alcohol in a neighboring state with relatively friendly alcohol policies (Figlio 1995). The border hopping is also relevant for parental consent laws.
} 
endogeneity using state characteristics as determinants of abortion services and the number of non-Ob/Gyn physicians in the state as my only instrument. ${ }^{19}$ The estimates of the first stage equation are reported in Table B-3.

I also test whether the effect of covariates included in $X_{g s t}$ differs across treatment and control groups and conclude that three variables (i.e., income, unemployment rate, and the border effect of parental involvement laws) have different effects on the pregnancy rates of younger and older women. To address this issue I add interactions terms between the treatment group and above mentioned variables to equation (B2). I repeat the test for birth and abortion rates and add corresponding interaction terms.

Finally, $\lambda$ in equation (B2) represents a vector of state fixed effects that captures all time invariant factors that affect pregnancy and abortion rates, and $\tau$ is a vector of time fixed effects that captures factors that are common across all states in a given time period.

Table B-4 contains DID estimates for pregnancy rates (columns 1-2), birth rates (columns 3-4), and abortion rates (columns 5-6); reported standard errors are clustered by state. For each dependent variable, I start with a naïve model that contains only indicators for the treatment group, the event, and the interaction between those two. Then I gradually add state and year fixed effects, then covariates, and finally interaction terms. I test the joint significance of the additional terms in the most "complex" model and in all cases I reject the null. Therefore, I focus only on the results from these models.

The coefficient of interest from a public policy point of view, $\beta_{3}$, is reported in Row (3) and indicates that there is no evidence that a low MLDA has a strong impact on teen pregnancy or birth rates. These estimated effects are not significant in a statistical or economic sense. ${ }^{20}$ The results from abortion model (Column 6) indicate that the presence of the MLDA of 18 or 19 increases teen abortion rates by 6.9 percent compared

\footnotetext{
${ }^{19}$ Blank et al. (1996) used two instruments: the total number of non-Ob/Gyn physicians and the total number of hospitals. The latter instrument raises concerns as it is likely correlated with the demand for abortion services. After Roe v. Wade many hospitals expanded their abortion services which might have had an effect on the demand for abortions. For discussion see Bond and Johnson (1982).

${ }^{20}$ For example, there are on average 85.15 pregnancies per 1,000 15-19 year-old women. The change of 3 percent would not significantly alter this rate.
} 
to the change in the control group (women 25-29 years old). However, this result is not robust and is sensitive to the choice of control group and covariates.

The estimates of other parameters reported in Table B-4 are as expected and consistent with the literature. As these estimates are not of the primary interest the discussion is omitted. 
Table B-1: Difference in means

\begin{tabular}{|c|c|c|c|c|}
\hline & & $\begin{array}{c}\text { MLDA is } \\
18 \text { or } 19\end{array}$ & $\begin{array}{l}\text { MLDA is } \\
20 \text { or } 21\end{array}$ & Difference \\
\hline \multicolumn{5}{|c|}{ 15-19 year-old women } \\
\hline \multirow{2}{*}{$\begin{array}{l}\text { Pregnancy rate } \\
\text { per } 1,000 \text { women }\end{array}$} & Mean & 87.40 & 82.58 & $4.82^{+}$ \\
\hline & Std. Dev. & 40.87 & 19.28 & \\
\hline \multirow{2}{*}{$\begin{array}{l}\text { Birth rate } \\
\text { per } 1,000 \text { women }\end{array}$} & Mean & 53.82 & 51.61 & $2.21 *$ \\
\hline & Std. Dev. & 14.35 & 12.98 & \\
\hline \multirow{2}{*}{$\begin{array}{l}\text { Abortion rate } \\
\text { per } 1,000 \text { women }\end{array}$} & Mean & 33.72 & 30.86 & 2.86 \\
\hline & Std. Dev. & 37.13 & 16.63 & \\
\hline \multicolumn{5}{|c|}{ 25-29 year-old women } \\
\hline \multirow{2}{*}{$\begin{array}{l}\text { Pregnancy rate } \\
\text { per } 1,000 \text { women }\end{array}$} & Mean & 138.62 & 137.82 & 0.81 \\
\hline & Std. Dev. & 21.54 & 18.88 & \\
\hline \multirow{2}{*}{$\begin{array}{l}\text { Birth rate } \\
\text { per } 1,000 \text { women }\end{array}$} & Mean & 114.89 & 116.17 & -1.28 \\
\hline & Std. Dev. & 17.39 & 18.40 & \\
\hline \multirow{2}{*}{$\begin{array}{l}\text { Abortion rate } \\
\text { per } 1,000 \text { women }\end{array}$} & Mean & 23.15 & 20.78 & 2.36 \\
\hline & Std. Dev. & 28.36 & 12.07 & \\
\hline
\end{tabular}

** significant at $1 \%$; * significant at $5 \%{ }^{+}{ }^{+}$significant at $10 \%$

Note: - Birth rate in a given year $t$ and state $s$ reflects the number of pregnancies conceived in that year

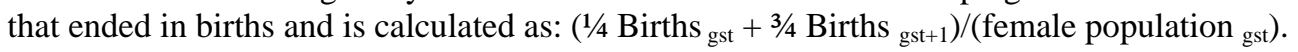


Table B-2: Descriptive statistics for variables used in the DID estimation

\begin{tabular}{|c|c|c|c|c|}
\hline & Obs & Mean & SD & Sources \\
\hline \multicolumn{5}{|l|}{ Age 15-19 } \\
\hline Pregnancy rate per 1000 women $^{a}$ & 572 & 85.15 & 32.69 & \multirow{2}{*}{$\begin{array}{l}\text { National center for health } \\
\text { statistics }\end{array}$} \\
\hline Birth rate per 1000 women $^{a}$ & 765 & 52.81 & 13.78 & \\
\hline Abortion rate per 1000 women $^{\text {a }}$ & 572 & 32.38 & 29.41 & CDC \\
\hline \multicolumn{5}{|l|}{ Age 25-29 } \\
\hline 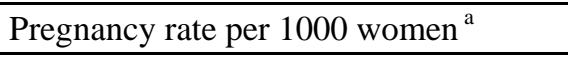 & 572 & 138.25 & 20.33 & \multirow{2}{*}{$\begin{array}{l}\text { National center for health } \\
\text { statistics }\end{array}$} \\
\hline 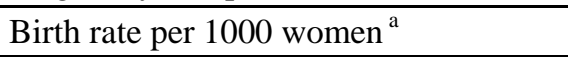 & 765 & 115.48 & 17.86 & \\
\hline Abortion rate per 1000 women $^{\text {a }}$ & 572 & 22.04 & 22.31 & CDC \\
\hline \multicolumn{5}{|l|}{ Age group invariant variables } \\
\hline MLDA is 18 years & 2295 & 0.35 & 0.48 & \multirow{4}{*}{$\begin{array}{l}\text { Wagenaar (1981), } \\
\text { O’Malley and Wagenaar } \\
\text { (1990), the National } \\
\text { Highway Traffic Safety } \\
\text { Administration website }\end{array}$} \\
\hline MLDA is 19 years & 2295 & 0.19 & 0.40 & \\
\hline MLDA is 20 years & 2295 & 0.05 & 0.23 & \\
\hline MLDA is 21 years & 2295 & 0.40 & 0.49 & \\
\hline $\begin{array}{l}\text { State per capita personal income, } \\
2000 \$\end{array}$ & 2295 & 21312.09 & 3663.56 & $\begin{array}{l}\text { Bureau of Economic } \\
\text { Analysis }\end{array}$ \\
\hline Max AFDC, 2000 \$ & 2295 & 735.09 & 278.53 & Welfare Benefit Data Base ${ }^{b}$ \\
\hline State unemployment rate & 2295 & 6.91 & 2.22 & Bureau of Labor Statistics \\
\hline Percent of black population & 2295 & 10.70 & 12.64 & U.S. Census Bureau \\
\hline Beer tax rate per gallon, $2000 \$^{c}$ & 2259 & 0.37 & 0.35 & $\begin{array}{l}\text { Brewers Almanac, } 1996, \\
\text { Beer Institute, Washington, } \\
\text { DC }\end{array}$ \\
\hline Number of abortion providers & 2295 & 51.82 & 85.88 & AGI \\
\hline Number of non-Ob/Gyn physicians ${ }^{d}$ & 2295 & 8411.46 & 10995.20 & Blank et al. (1996) \\
\hline \multicolumn{5}{|l|}{ Age group variant variables } \\
\hline Medicaid restrictions $^{\text {e }}$ & 2295 & 0.51 & 0.48 & $\begin{array}{l}\text { Blank et al. (1996), New } \\
\text { (2004), and NARAL }\end{array}$ \\
\hline Parental consent and notification laws ${ }^{\mathrm{f}}$ & 2295 & 0.03 & 0.17 & $\begin{array}{l}\text { Merz (1995), Haas-Wilson } \\
\text { (1996), Greenberger and } \\
\text { Connor (1992), New } \\
\text { (2004), and NARAL } \\
\text { website }\end{array}$ \\
\hline $\begin{array}{l}\text { Number of unrestricted borders for } \\
\text { consent }^{\mathrm{g}}\end{array}$ & 2295 & 4.23 & 1.79 & \multirow{2}{*}{ Author's calculation ${ }^{\mathrm{i}}$} \\
\hline Number of unrestricted borders for beer ${ }^{h}$ & 2295 & 3.31 & 2.32 & \\
\hline
\end{tabular}

${ }^{\mathbf{a}}$ Statistic is restricted to the age group. ${ }^{\mathbf{b}}$ Retrieved from R.A. Moffitt's webpage on 08/04/2009: www.econ.jhu.edu/people/moffitt/datasets.html ${ }^{\mathbf{c}}$ The number of observations differs due to missing values for beer tax in Hawaii (before 1986 the tax rate was calculated as a percentage of the wholesale price). ${ }^{\mathbf{d}}$ Calculated as a difference between the total number of physicians and $\mathrm{Ob} / \mathrm{Gyn}$ physicians. ${ }^{\mathbf{e}}$ Variable range from 0 to 1 , where 1 indicates a presence of the restrictive law and 0 - no restrictions. Values between 0 and 1 reflect changes that occurred during the calendar year (see Blank et al. (1996) for a description). ${ }^{\mathrm{f}}$ For 15-19 years old coded similar to the Medicaid restrictions variable. For 25-29 year-old values are set to $0{ }^{\mathrm{g}}$ For $15-19$ year-old: For each state $s$, this variable equals the number of border states that do not enforce a parental notification/consent law. For 25-29 year-old: this variable equals the number of borders. ${ }^{\text {h }}$ For 15-19 year-old: For each state $s$, this variable equals the number of border states that have a lower MLDA than state $s$. For 25-29 year-old: this variable equals the number of border states. ${ }^{\mathbf{i}}$ The alternative measure - a weighted average of policies in states that border state $s$, where weights correspond to the length of the border line between state $s$ and each border state - yields similar results. 


\section{Table B-3: First stage regression}

\begin{tabular}{lcc}
\hline Dependent variable: natural logarithm of abortion providers & & \\
\hline & Coefficient & Std. error \\
Log non-Ob/Gyn physicians (instrument) & $0.390^{* *}$ & $(0.07)$ \\
Medicaid funding restrictions for abortions & -0.019 & $(0.02)$ \\
Enforced parental consent and notification laws & -0.019 & $(0.02)$ \\
Border effect of enforced parental involvement laws & $0.001^{* *}$ & $(0.00)$ \\
Governor/senate/house are Republicans & $0.075^{* *}$ & $(0.02)$ \\
Marriage rate per 1,000 females & 0.000 & $(0.00)$ \\
Percent of teen female in fertile population & $0.025^{* *}$ & $(0.01)$ \\
Percent of black population & $-0.018^{* *}$ & $(0.01)$ \\
Female labor force participation rate & $0.016^{* *}$ & $(0.00)$ \\
Log real personal disposable income, 2000\$ & 0.103 & $(0.11)$ \\
Unemployment rate in a state & $-0.022^{* *}$ & $(0.00)$ \\
Population density & $0.001^{* *}$ & $(0.00)$ \\
State and year fixed effects & yes & \\
Number of observations & 2295 & \\
R square & 0.9794 & \\
\hline
\end{tabular}

${ }^{* *}$ significant at $1 \%$; ${ }^{*}$ significant at $5 \% ;{ }^{+}$significant at $10 \%$ 
Table B-4: Difference-in-Difference estimates using 25-29 years old women as a control group (1974-1988)

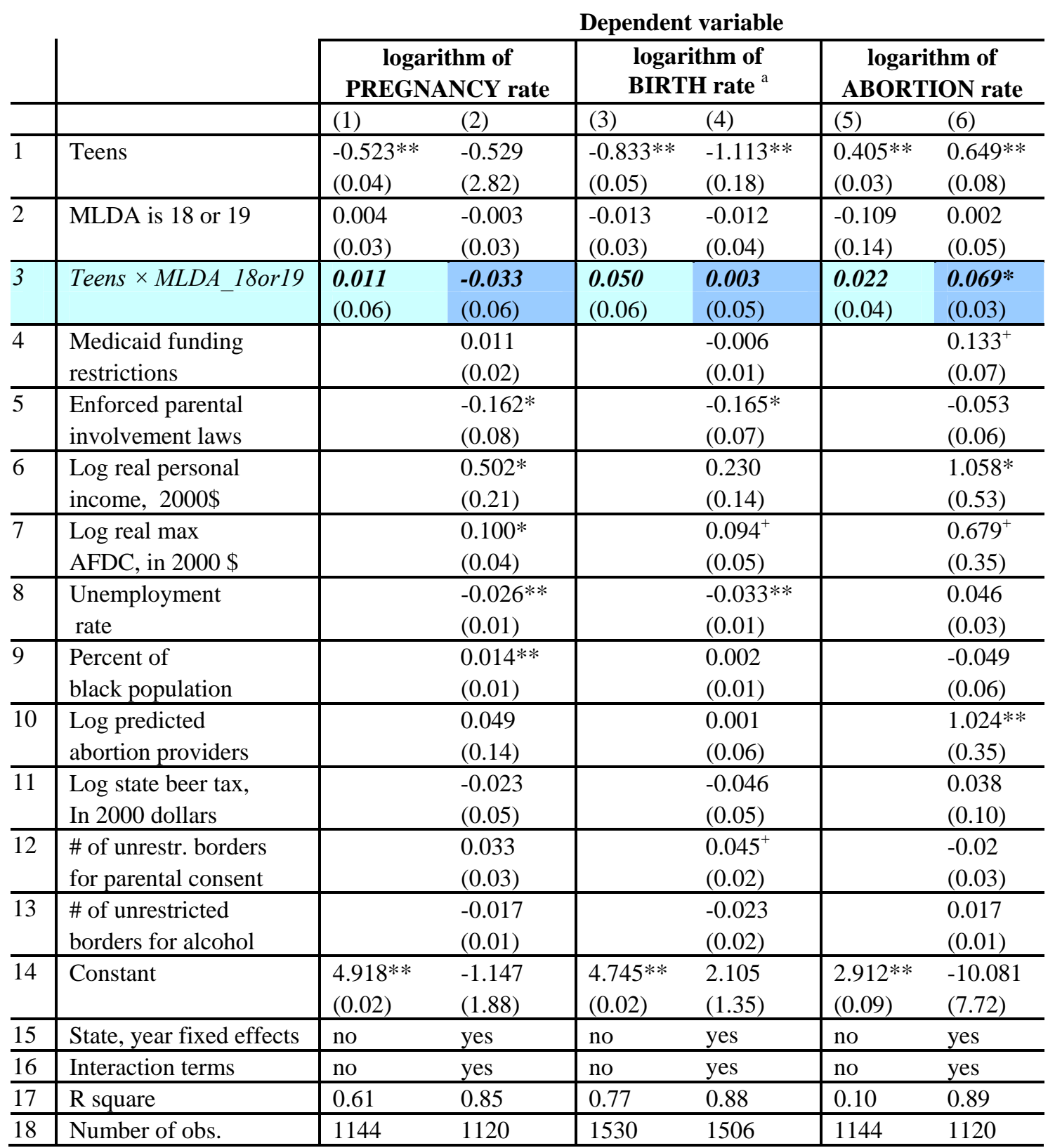

Note. - Interaction terms are the following: specification (2) includes (teens*income),

(teens*unemployment), and (teens*parental consent); specification (4): (teens*unemployment), (teens*providers), and (teens*unrestricted alcohol); and specification (4): (teens*black),

(teens*unemployment), and (teens*parental consent).

** significant at 1\%; * significant at 5\%; + significant at $10 \%$. Standard errors clustered by state are in parentheses. I use the F-test to test model (2) v. (1); (4) v. (3), and (6) v. (5); in all cases I reject the null.

${ }^{\text {a }}$ For each age group $g$, birth rate in a given year $t$ and state $s$ reflects the number of pregnancies conceived in that year that ended in births and is calculated as: $\left(1 / 4\right.$ Births $_{\text {gst }}+3 / 4$ Births $\left.{ }_{\text {gst }+1}\right) /($ female population gst $)$. 


\section{Appendix C}

Table C-1: Probit coefficient estimates for pregnancy model by age group

Dependent variable: pregnancy status that equals 1 if pregnant, 0 otherwise

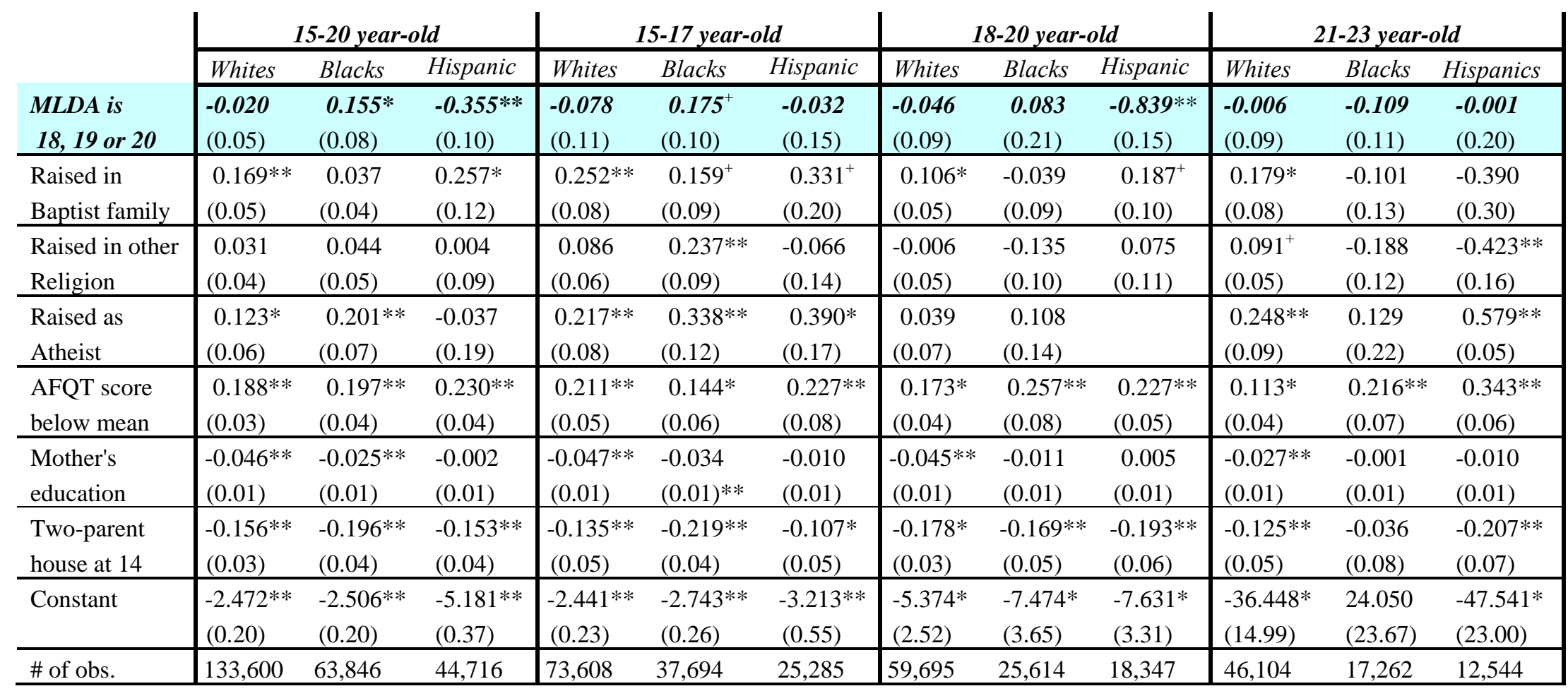

** significant at 1\%; * significant at 5\%; + significant at $10 \%$. Standard errors clustered by state. Person-month observations. All models include state, year, and calendar month fixed effects as well as age cubic polynomial. Excluded category for religion is women raised in Catholic families. 


\section{Appendix C}

Table C-2: Probit coefficient estimates for birth outcome conditional on pregnancy by age group-race combination

Dependent variable equals 1 if $1^{\text {st }}$ pregnancy ended in birth, 0 otherwise;

\begin{tabular}{|c|c|c|c|c|c|c|c|c|c|c|}
\hline & \multicolumn{3}{|c|}{ 15-20 year-old } & \multicolumn{3}{|c|}{ 15-17 year-old } & \multicolumn{3}{|c|}{ 18-20 year-old } \\
\hline & & Whites & Blacks & Hispanics & Whites & Blacks & Hispanics $^{a}$ & Whites & Blacks & Hispanics $^{a}$ \\
\hline (1) & $\begin{array}{l}M L D A \text { is } \\
18,19 \text {, or } 20\end{array}$ & $\begin{array}{c}0.403 \\
(0.26) \\
\end{array}$ & $\begin{array}{l}-0.242 \\
(0.24)\end{array}$ & $\begin{array}{l}-0.956^{*} \\
(0.46) \\
\end{array}$ & $\begin{array}{r}0.232 \\
(0.35) \\
\end{array}$ & $\begin{array}{l}-0.260 \\
(0.26) \\
\end{array}$ & $\begin{array}{l}-8.775^{* *} \\
(0.53) \\
\end{array}$ & $\begin{array}{r}\mathbf{0 . 6 1 5} \\
(0.47)\end{array}$ & $\begin{array}{l}-0.568 \\
(0.46)\end{array}$ & $\begin{array}{l}-6.530^{* *} \\
(0.47) \\
\end{array}$ \\
\hline (2) & $\begin{array}{l}\text { Raised in } \\
\text { Baptist family }\end{array}$ & $\begin{array}{c}0.219 \\
(0.16) \\
\end{array}$ & $\begin{array}{l}-0.318 \\
(0.31) \\
\end{array}$ & $\begin{array}{l}-0.063 \\
(0.31) \\
\end{array}$ & $\begin{array}{l}-0.079 \\
(0.32) \\
\end{array}$ & $\begin{array}{l}-0.797 \\
(0.58) \\
\end{array}$ & $\begin{array}{l}-1.591^{* *} \\
(0.56)\end{array}$ & $\begin{array}{r}0.323 \\
(0.22) \\
\end{array}$ & $\begin{array}{r}0.076 \\
(0.40) \\
\end{array}$ & $\begin{array}{r}0.280 \\
(0.45) \\
\end{array}$ \\
\hline (3) & $\begin{array}{l}\text { Raised in other } \\
\text { Religion }\end{array}$ & $\begin{array}{l}-0.227^{*} \\
(0.10)\end{array}$ & $\begin{array}{l}-0.324 \\
(0.34) \\
\end{array}$ & $\begin{array}{l}-0.281 \\
(0.25)\end{array}$ & $\begin{array}{l}-0.370 \\
(0.26) \\
\end{array}$ & $\begin{array}{l}-0.563 \\
(0.65) \\
\end{array}$ & $\begin{array}{l}-0.136 \\
(0.77) \\
\end{array}$ & $\begin{array}{l}-0.183 \\
(0.16) \\
\end{array}$ & $\begin{array}{l}-0.254 \\
(0.40)\end{array}$ & $\begin{array}{l}-0.476 \\
(0.41) \\
\end{array}$ \\
\hline (4) & $\begin{array}{l}\text { Raised as } \\
\text { Atheist }\end{array}$ & $\begin{array}{r}0.129 \\
(0.31) \\
\end{array}$ & $\begin{array}{l}-0.571 \\
(0.50) \\
\end{array}$ & $\begin{array}{l}-0.709 \\
(0.57) \\
\end{array}$ & $\begin{array}{r}0.095 \\
(0.32) \\
\end{array}$ & $\begin{array}{l}-1.513^{+} \\
(0.82) \\
\end{array}$ & $\begin{array}{l}-0.032 \\
(0.57) \\
\end{array}$ & $\begin{array}{r}0.063 \\
(0.47) \\
\end{array}$ & $\begin{array}{c}0.196 \\
(0.70) \\
\end{array}$ & \\
\hline (5) & $\begin{array}{l}\text { AFQT score } \\
\text { below mean }\end{array}$ & $\begin{array}{l}0.537^{* *} \\
(0.13)\end{array}$ & $\begin{array}{l}0.638^{* *} \\
(0.20)\end{array}$ & $\begin{array}{l}0.840^{* *} \\
(0.15)\end{array}$ & $\begin{array}{l}0.739 * * \\
(0.22)\end{array}$ & $\begin{array}{l}0.591 * \\
(0.27) \\
\end{array}$ & $\begin{array}{l}2.407^{* *} \\
(0.54)\end{array}$ & $\begin{array}{l}0.445^{* *} \\
(0.15)\end{array}$ & $\begin{array}{l}0.876^{* *} \\
(0.28)\end{array}$ & $\begin{array}{l}1.083^{* *} \\
(0.15) \\
\end{array}$ \\
\hline (6) & $\begin{array}{l}\text { Mother's } \\
\text { education }\end{array}$ & $\begin{array}{l}-0.103^{* *} \\
(0.03)\end{array}$ & $\begin{array}{l}-0.038 \\
(0.02)\end{array}$ & $\begin{array}{l}-0.112^{* *} \\
(0.02)\end{array}$ & $\begin{array}{l}-0.074^{+} \\
(0.04)\end{array}$ & $\begin{array}{l}-0.183^{* *} \\
(0.06)\end{array}$ & $\begin{array}{l}-0.261^{* *} \\
(0.06)\end{array}$ & $\begin{array}{l}-0.151^{* *} \\
(0.05)\end{array}$ & $\begin{array}{l}0.089 * * \\
(0.03)\end{array}$ & $\begin{array}{l}-0.108 * * \\
(0.02)\end{array}$ \\
\hline (7) & $\begin{array}{l}\text { Two-parent } \\
\text { household at } 14\end{array}$ & $\begin{array}{l}-0.196^{+} \\
(0.11) \\
\end{array}$ & $\begin{array}{l}-0.192 \\
(0.16) \\
\end{array}$ & $\begin{array}{r}0.289 \\
(0.29) \\
\end{array}$ & $\begin{array}{l}-0.258 \\
(0.27) \\
\end{array}$ & $\begin{array}{r}0.010 \\
(0.24) \\
\end{array}$ & $\begin{array}{r}0.555 \\
(0.59) \\
\end{array}$ & $\begin{array}{l}-0.074 \\
(0.14) \\
\end{array}$ & $\begin{array}{l}-0.264 \\
(0.17) \\
\end{array}$ & $\begin{array}{r}0.280 \\
(0.35) \\
\end{array}$ \\
\hline (8) & Constant & $\begin{array}{l}5.934^{* *} \\
(0.45)\end{array}$ & $\begin{array}{l}11.512^{* *} \\
(0.80)\end{array}$ & $\begin{array}{l}3.333^{* *} \\
(0.66)\end{array}$ & $\begin{array}{l}11.221^{* *} \\
(0.78)\end{array}$ & $\begin{array}{l}14.571^{* *} \\
(1.84)\end{array}$ & $\begin{array}{l}-10.919^{* *} \\
(1.26) \\
\end{array}$ & $\begin{array}{r}15.213 \\
(13.24) \\
\end{array}$ & $\begin{array}{l}-29.526 \\
(26.66)\end{array}$ & $\begin{array}{r}1.069 \\
(14.64) \\
\end{array}$ \\
\hline & \# of observations & 706 & 583 & 330 & 266 & 307 & 117 & 414 & 255 & 194 \\
\hline
\end{tabular}

** significant at 1\%; * significant at 5\%; + significant at 10\%. Standard errors clustered by state. Sample is limited to women who are pregnant. All models include state and year fixed effects and age cubic polynomial. Due to small sample sizes, dummies for calendar months are excluded. Excluded category for religion is women raised in Catholic families. ${ }^{\text {a }}$ The large estimates might be driven by small sample size, rare non-event occurrence, and a large number of covariates included in the model. 
Appendix C (Continued)

Table C-3: Probit coefficient estimates for abortion outcome conditional on pregnancy by age group-race combination

Dependent variable equals 1 if $1^{\text {st }}$ pregnancy ended in abortion, 0 otherwise

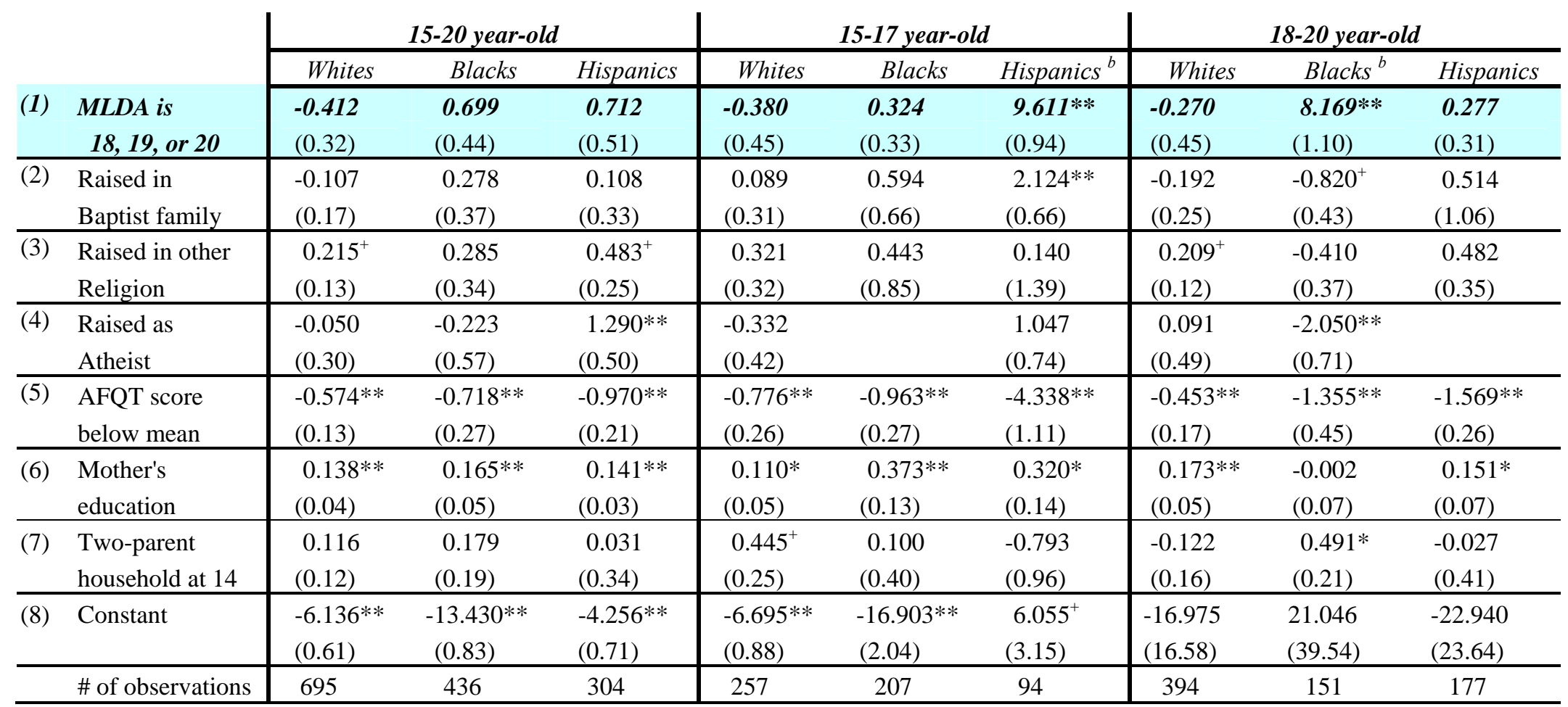

** significant at 1\%; * significant at 5\%; + significant at $10 \%$. Standard errors clustered by state. Sample is limited to women who are pregnant. All models include state and year fixed effects and age cubic polynomial. Due to small sample sizes, dummies for calendar months are excluded. Excluded category for religion is women raised in Catholic families. ${ }^{\mathbf{b}}$ The large estimates might be driven by small sample size and rare event occurrence. For example, there were 22 abortions reported among 192 pregnant 15-17 years old Hispanics; 29 abortions among 345 pregnant 18-20 years old Blacks. 
Appendix C (Continued)

Table C-4: Probit coefficient estimates for pregnancy, birth, and abortion models, 18-20 year-old women

Dependent variable in pregnancy model: pregnancy status that equals 1 if pregnant, 0 otherwise

Dependent variable in birth model equals 1 if $1^{\text {st }}$ pregnancy ended in birth, 0 otherwise; the sample is limited to pregnant women

Dependent variable in abortion model equals 1 if $1^{\text {st }}$ pregnancy ended in abortion, 0 otherwise; the sample is limited to pregnant women

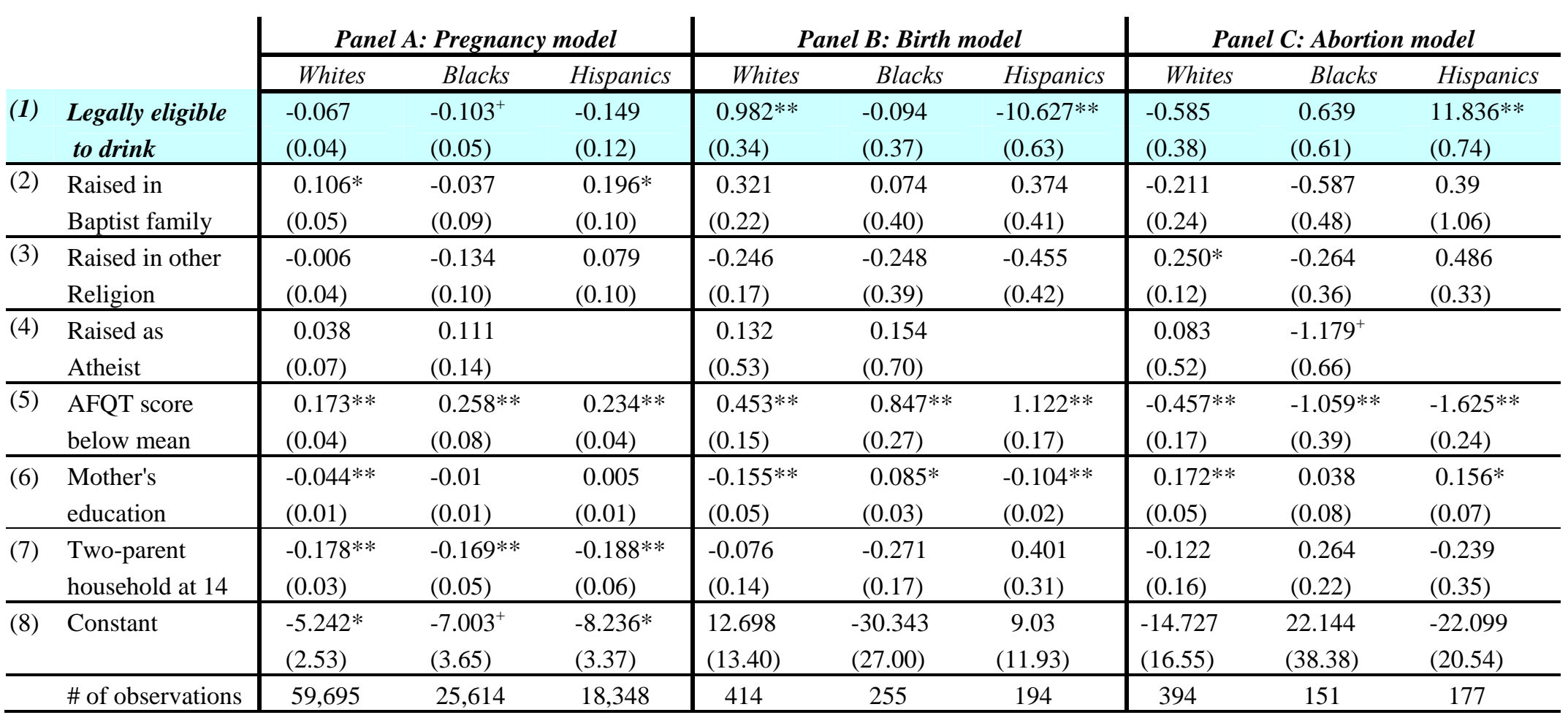

** significant at 1\%; * significant at 5\%; + significant at 10\%. Standard errors clustered by state. Person-month observations. All models include state and year fixed effects and age cubic polynomial. In addition, pregnancy model includes calendar month fixed effects. Excluded category for religion is women raised in Catholic families. Additional covariates mostly did not improve models' fit. 